$\frac{26}{915} 18550$

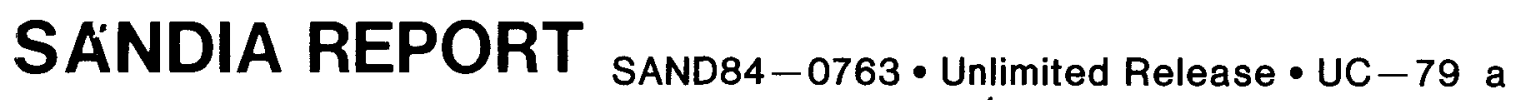

$D R-1271-8$

Printed August 1985

$I-22800$

- Sandia Sodium Purification Loop

(SNAPL) Description and Operations

Manual

Russell U. Acton, Richard L. Weatherbee, Lawrence A. Smith

Floyd L. Mastin, Kenyon E. Nowotny

Prepared by

Sandia National Laboratories

Albuquerque, New Mexico 87185 and Livermore, California 94550

for the United States Department of Energy

under Contract DE-AC04-76DP00789 
Issued by Sandia National Laboratories, operated for the United States Department of Energy by Sandia Corporation.

NOTICE: This report was prepared as an account of work sponsored by an agency of the United States Government. Neither the United States Government nor any agency thereof, nor any of their employees, nor any of their contractors, subcontractors, or their employees, makes any warranty, ex-
press or implied, or assumes any legal liability or responsibility for the press or implied, or assumes any legal liability or responsibility for the accuracy, completeness, or usefulness of any information, apparatus, prod-
uct, or process disclosed, or represents that its use would not infringe privately owned rights. Reference herein to any specific commercial product, process, or service by trade name, trademark, manufacturer, or otherwise, does not necessarily constitute or imply its endorsement, recommendation, or favoring by the United States Government, any agency thereof or any of their contractors or subcontractors. The views and opinions expressed herein do not necessarily state or reflect those of the United States Government any agency thereof or any of their contractors or subcontractors.

Printed in the United States of America Available from

National Technical Information Service

U.S. Department of Commerce

5285 Port Royal Road

Springfield, VA 22161

NTIS price codes

Printed copy: A05

Microfiche copy: A01 


\section{DISCLAIMER}

This report was prepared as an account of work sponsored by an agency of the United States Government. Neither the United States Government nor any agency Thereof, nor any of their employees, makes any warranty, express or implied, or assumes any legal liability or responsibility for the accuracy, completeness, or usefulness of any information, apparatus, product, or process disclosed, or represents that its use would not infringe privately owned rights. Reference herein to any specific commercial product, process, or service by trade name, trademark, manufacturer, or otherwise does not necessarily constitute or imply its endorsement, recommendation, or favoring by the United States Government or any agency thereof. The views and opinions of authors expressed herein do not necessarily state or reflect those of the United States Government or any agency thereof. 


\section{DISCLAIMER}

Portions of this document may be illegible in electronic image products. Images are produced from the best available original document. 
SAND $-84-0763$

DE85 017353

SAND84-0763 - Category UC-79 a

\title{
SANDIA SODIUM PURIEICATION LOOP (SNAPL) \\ DESCRIPTION AND OPERATIONS MANUAL
}

\author{
R. U. Acton \\ R. L. Weatherbee \\ L. A. Smith \\ E. L. Mastin \\ K. E. Nowotny
}

Sandia National Laboratories

Albuquerque, New Mexico 87185

ABSTRACT

Sandia's Sodium purification Loop was constructed to purify sodium for fast reactor safety experiments. An oxide impurity of less than 10 parts per million is required by these in-pile experiments. Commercial, reactor grade sodium is purchased in $180 \mathrm{~kg}$ drums. The sodium is melted and transferred into the unit. The unit is of a loop design and purification is accomplished by "cold trapping". Sodium purified in this loop has been chemically analysed at one part per million oxygen by weight.

\section{DISCLAIMER}

This report was prepared as an account of work sponsored by an agency of the United States Government. Neither the United States Government nor any agency thereof, nor any of their employees, makes any warranty, express or implied, or assumes any legal liability or responsibility for the accuracy, completeness, or usefulness of any information, apparatus, product, or process disclosed, or represents that its use would not infringe privately owned rights. Reference herein to any specific commercial product, process, or service by trade name, trademark, manufacturer, or otherwise does not necessarily constitute or imply its endorsement, recommendation, or favoring by the United States Government or any agency thereof. The views and opinions of authors expressed herein do not necessarily state or reflect those of the United States Government or any agency thereof.

NSTIER

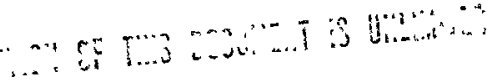




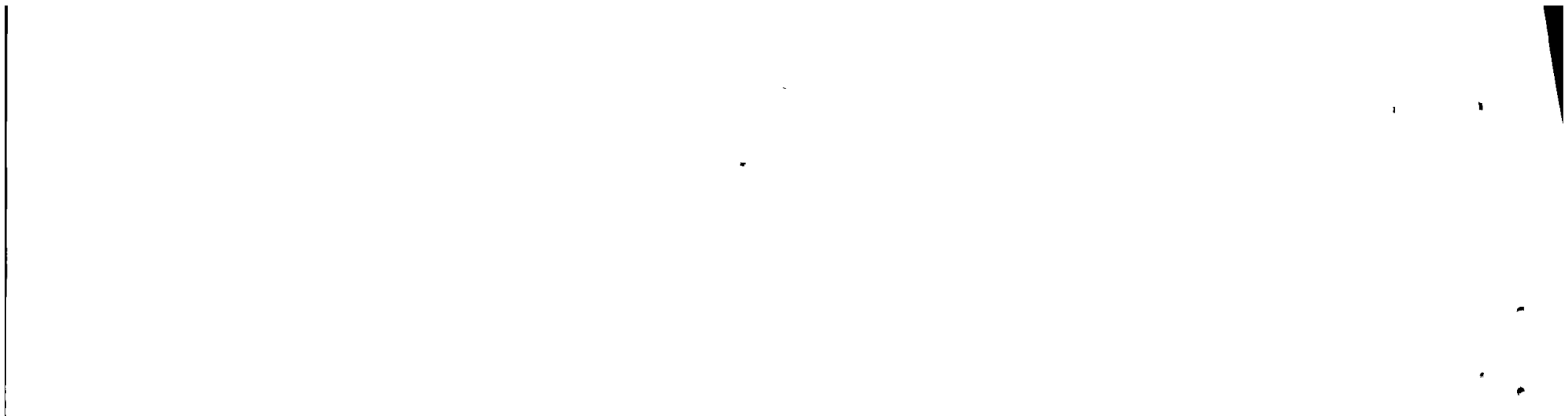

-

- 
THEORY OF OPERATION

ELECTROMAGNETIC PUMP

MAGNETIC FLOWMETERS • • • • • • • • • •

POWER AND CONTROL

COMPUTER

FILLING AND CIRCULATING SODIUM IN THE LOOP • •

ACKNOWLEDGEMENT

APPENDIX A LOAD AND EXECUTE COMPUTER CONTROL PROGRAM •. . . . . . . . . . . . . . .

APPENDIX B SODIUM CHEMICAL ANALYSIS . • . . • • •

APPENDIX D SODIUM LOOP DRAWING LIST AND REFERENCED DRAWINGS 

Figure 1 Solubility of oxygen in sodium . . . . . . .

Figure 2 Solubility of hydrogen in sodium . . . . .

Figure 3 Loop schematic of sodium purification loop .................. 9

Figure 4 Cold trap . . . . . . . . . . . . . 10

Figure 5 Lefthand rule . . . . . . . . . . . . 11

Figure 6 Electromagnetic pump flow characteristics . 13

Figure 7 Two-stage electromagnetic pump . . . . . . . 14

Figure 8 Cover gas system . . . . . . . . . . . 15

Figure 9 Bellows valve . . . . . . . . . . . 17

Figure 10 Schematic of electromagnetic flowmeter . . . 19

Figure 11 Flowmeter and effect . . . . . . . . . 21

Figure 12 Flowmeter temperature correction factor • • 21

Figure 13 Thermocouple well . . . . . . . . . . . . APPENDIX

Figure 14 Thermocouple locations . . . . . . . . . . APPENDIX

Figure $15 \quad$ Schematic of Westinghouse oxygen meter . . . 23

Figure 16 Oxygen meter output . • . . . . . . . . . 24

figure 17 Probe level detector schematic . . . . • . 26

Figure 18 Bubble manometer level detector schematic . 29

Figure 19 Sodium loop instrumentation, alarms and
control schematic . . . . . . . . . 30

Figure 20 Typical control circuit . . . . . . . . . 32

Figure 21 Screen display for one scan of control program ............ . . 37

Figure 22 Screen display in large type mode (Control Program Keystroke "Big One") . . . . . . 
TABLE I

Procurement specification guide . . . .

TABLE II Solubility of oxygen in sodium . . . . . .

TABLE II Solubility of hydrogen in sodium . . . . .

TABLE IV

Cleaning procedure

TABLE V

Tanks T1\& T2 elevation vs. volume . . •

TABLE VI

Sodium purification loop thermocouple/ heater connections $34-36$

TABLE VII Checklist, filling the loop with sodium.. 


\section{BACKGROUND}

Sandia National Laboratories is conducting research into various safety aspects of liquid metal fast breeder reactors (LMFBR). Molten sodium is used as the core coolant heat transfer fluid in this type of reactor. Experiments are to be performed on the coolability of urania fuel debris beds in sodium as well as other experiments involving interaction of fuel with sodium. These experiments will be run in Sandia's Annular Core Research Reactor (ACRR), where neutronic heating will simulate decay heating or other histories associated with applicable accident scenarios. The results of these experiments will aid in the development and validation of models for predicting the consequences of reactor accidents.

Sodium is available from numerous suppliers in several gradescommercial, high purity, reactor, etc. However, no universally accepted standard exists for specifying the purity of sodium and, as a consequence, the impurities analysis must be specified for the particular application.

The impurities in sodium come from two areas, 1) those impurities that are contaminants from the manufacturing process or source materials and, 2) those impurities that result from contact with other materials during the transport, storage and use of the sodium. Calcium, carbon and potassium are impurities left in, or as a result of, the manufacturing process. Calcium chloride is added to the electrolytic cell to reduce the melting point of the sodium chloride. Carbon comes from the graphite electrodes used in the fused salt process. Potassium chloride is a contaminant in sodium chloride. potassium is the largest single impurity typically found in sodium, but potassium and sodium are similar in their properties and this impurity is of little consequence in usual applications. Oxygen and hydrogen are impurities picked up in the transportation and use of sodium. The oxygen comes from contamination by the air through leaks and connections and as a contaminant in the cover gas system. Hydrogen comes from contact with moisture or hydrocarbons. Hydrogen is also generated in a reactor steam generator where the water oxidizes the steel tubes. Hydrogen readily diffuses through the tubes into the secondary sodium system. If it is not continuously cold trapped there, it diffuses into the primary sodium system.

The reasons for limiting the impurities in sodium are several. Eirst, impurities may cause metallurgical changes in structural materials and fuel cladding. Second, some impurities affect the neutron moderating process. A tentative purchase specification(1) for sodium is shown in Table $I$. Oxygen and hydrogen are left blank and are typically controlled by an on-line saturation temperature ${ }^{+}$ of $200^{\circ} \mathrm{C}$.

\footnotetext{
Fexplained in Theory of operation section.
} 
Since the Sandia experiments are static as opposed to the flowing cooling systems of a reactor, a sodium loop has been built to bring the oxygen and hydrogen levels of reactor grade sodium to those typically found in an LMFBR, i.e., <lo ppmw.

THEORY OF OPERATION

The solubilities of oxygen and hydrogen in sodium are temperature dependent. The solubility increases with increasing temperature for both elements. The sodium purification loop is a closed recirculating system in which sodium is circulated at some elevated temperature. The loop has several parallel legs for such purposes as pumps, flow meters, instrumentation, heaters and etc. In one of these parallel legs is a cold trap. In the cold trap, the temperature of the flowing sodium is dropped to a temperature several hundred degrees celsius below the temperature of the rest of the loop. The oxygen and hydrogen that were in solution at the higher temperature are now supersaturated at the lower temperature and precipitate out of the sodium as sodium oxide ( $\mathrm{Na}_{2} \mathrm{O}$ ) and sodium hydride (NaH). The cold trap contains a fine stainless steel wire gauze which traps the precipitates. The sandia loop is typically operated at $400^{\circ}-120^{\circ} \mathrm{C}$. At $400^{\circ} \mathrm{C}$, the solubility of oxygen in sodium is 412 ppmw and at $120^{\circ} \mathrm{C}$ it is 1 ppmw. These values are those proposed by Noden $(2)$. In 1973, Noden correlated the data from 217 separate analyses of the solubility of oxygen in sodium by a least squares technique. The solubility thus derived is given by the equation:

$$
\log _{10}\left[0_{x}\right]_{\text {ppmw }}=6.1579-2384.2 / T
$$

where

$O_{x}$ is oxygen solubility is parts per million by weight

$T$ is temperature in Kelvin.

A plot of equation 1 is shown in Figure 1. The solubility is tabulated in Table II. Sreedharan and Gnanamoorthy(3) resurveyed the literature in 1979 and concluded, "Noden's solubility equation is shown to be the most rational choice for the Na-O system."

The solubility of hydrogen in liquid sodium is reported by Whittingham $(4)$ to be given by the equation

$$
\log _{10}[\mathrm{H}]_{\mathrm{ppmw}}=6.467-3023 / \mathrm{T}
$$

where

$H$ is hydrogen solubility in parts per million by weight and

$T$ is temperature in Kelvin.

This least squares fit of experimental data is plotted in Figure 2 and tabulated in Table III. 


\section{TABLE I Procurement specification Guide}

\begin{tabular}{|c|c|c|c|}
\hline Impurity & $\begin{array}{c}\text { Maximum } \\
\text { Concentration } \\
\text { wppm } \\
\end{array}$ & Impurity & $\begin{array}{c}\text { Maximum } \\
\text { Concentration } \\
\text { wppm } \\
\end{array}$ \\
\hline Aluminum & 10 & Lithium & 10 \\
\hline Barium & 10 & Mercury & 35 \\
\hline Boron & $\mathrm{x}$ & Magnesium & $\mathbf{x}$ \\
\hline Cadmium & $\mathrm{x}$ & Manganese & $\mathrm{x}$ \\
\hline Calcium & 10 & Nickel & 10 \\
\hline Carbon & 30 & Nitrogen & 5 \\
\hline Cesium & 5 & oxygen & * \\
\hline Chromium & 10 & Phosphorus & 20 \\
\hline Cobalt & $x$ & Potassium & 200 \\
\hline Copper & 5 & Rubidium & 50 \\
\hline Hydrogen & * & Silicon & 10 \\
\hline Indium & $\mathrm{x}$ & Silver & $\mathrm{x}$ \\
\hline Iron & 25 & strontium & 10 \\
\hline \multirow[t]{3}{*}{ Lead } & 10 & Sulfur & 30 \\
\hline & & Tin & 10 \\
\hline & & Halogens & 20 \\
\hline
\end{tabular}

$x$ Composition limits not set

* To be controlled in application 


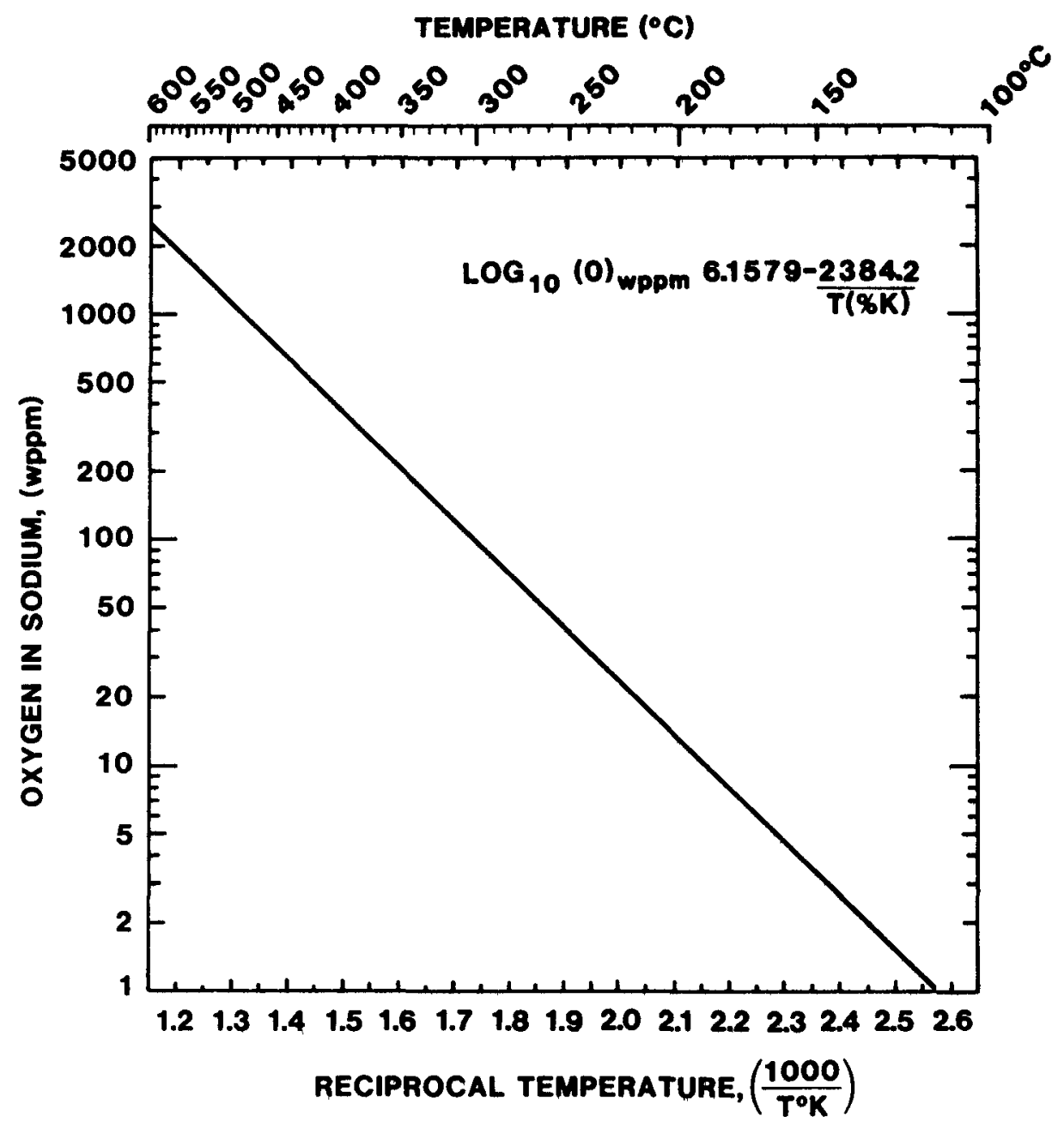

Figure 1. Solubility of oxygen in Sodium 
Table II

Solubility of oxygen in sodium

\begin{tabular}{|c|c|c|c|}
\hline $\begin{array}{l}\text { Temp } \\
{ }^{\circ} \mathrm{C} \\
\end{array}$ & $\begin{array}{l}\text { oxygen } \\
\text { ppmw } \\
\end{array}$ & $\begin{array}{l}\text { Temp } \\
{ }^{\circ} \mathrm{C} \\
\end{array}$ & $\begin{array}{l}\text { oxygen } \\
\text { ppmw }\end{array}$ \\
\hline 120 & 1.2 & 275 & 64.1 \\
\hline 125 & 1.5 & 280 & 70.2 \\
\hline 130 & 1.7 & 285 & 76.8 \\
\hline 135 & 2.1 & 290 & 83.8 \\
\hline 140 & 2.4 & 295 & 91.3 \\
\hline 145 & 2.8 & 300 & 99.3 \\
\hline 150 & 3.3 & 305 & 107.9 \\
\hline 155 & 3.9 & 310 & 117.0 \\
\hline 160 & 4.5 & 315 & 126.8 \\
\hline 165 & 5.2 & 320 & 137.2 \\
\hline 170 & 6.0 & 325 & 148.2 \\
\hline 175 & 6.9 & 330 & 160.0 \\
\hline 180 & 7.8 & 335 & 172.3 \\
\hline 185 & 9.0 & 340 & 185.6 \\
\hline 190 & 10.2 & 345 & 199.5 \\
\hline 195 & 11.6 & 350 & 214.3 \\
\hline 200 & 13.1 & 355 & 229.8 \\
\hline 205 & 14.8 & 360 & 246.3 \\
\hline 210 & 16.7 & 365 & 263.6 \\
\hline 215 & 18.7 & 370 & 281.8 \\
\hline 220 & 21.0 & 375 & 301.0 \\
\hline 225 & 23.5 & 380 & 321.2 \\
\hline 230 & 25.2 & 385 & 342.4 \\
\hline 235 & 29.1 & 390 & 364.6 \\
\hline 240 & 32.4 & 395 & 387.9 \\
\hline 245 & 35.9 & 400 & 412.3 \\
\hline 250 & 39.7 & & \\
\hline 255 & 43.9 & & \\
\hline 260 & 48.4 & & \\
\hline 265 & 53.2 & & \\
\hline 270 & 58.5 & & \\
\hline
\end{tabular}




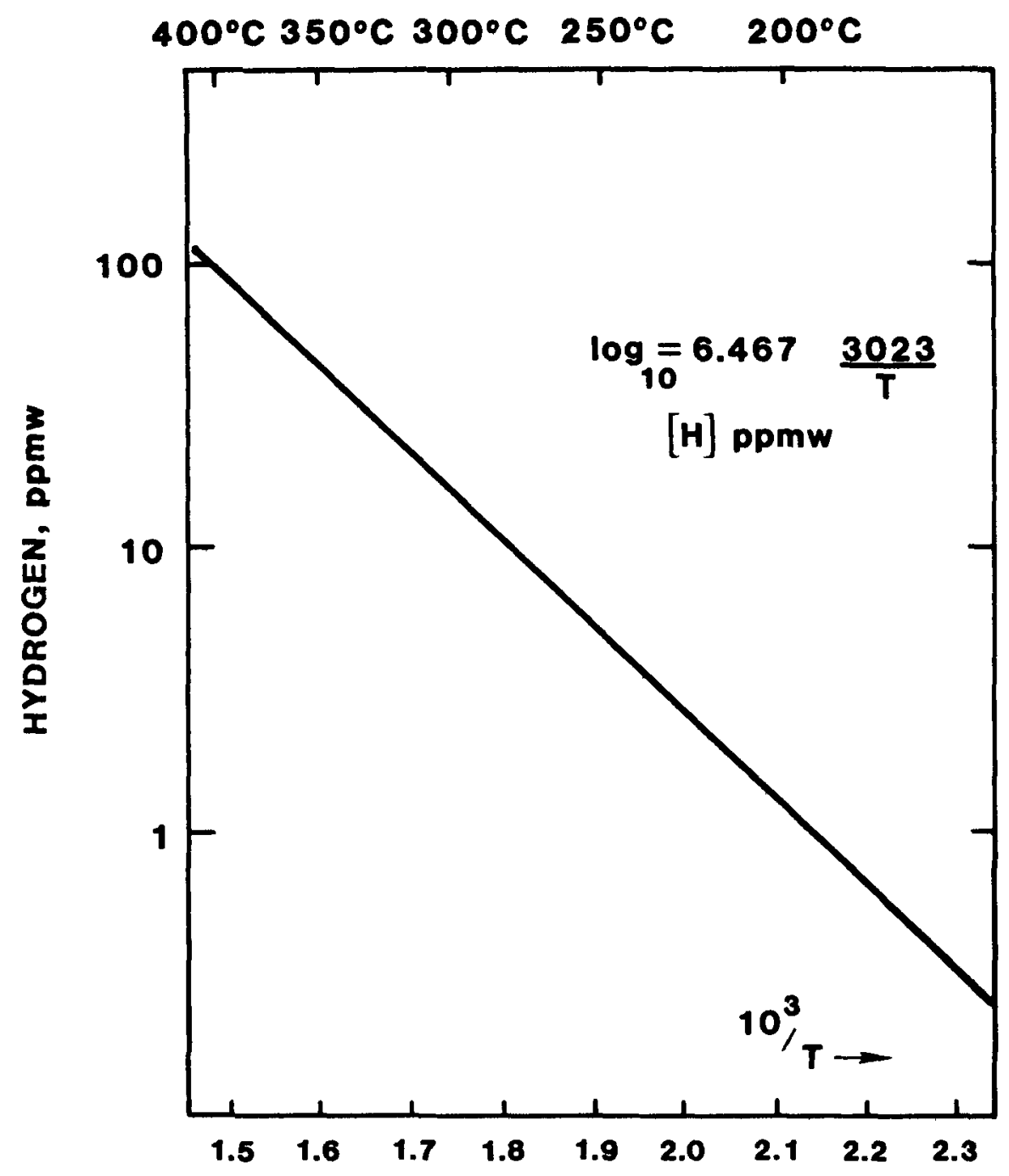

Figure 2. Solubility of Hydrogen in Sodium 
Table III

solubility of Hydrogen in sodium

\begin{tabular}{l}
$\begin{array}{c}\text { Temp } \\
{ }^{\circ} \mathrm{C}\end{array}$ \\
\hline 120 \\
130 \\
140 \\
150 \\
160 \\
170 \\
180 \\
190 \\
200 \\
250 \\
300 \\
350 \\
400
\end{tabular}

Hydrogen

ppmw

0.06

0.09

0.14

0.21

0.31

0.44

0.62

0.87

1.19

4.86

15.53

41.18

94.44 
From these solubility data, it can be seen that hydrogen is less soluble in sodium than is oxygen and that the cold trap reduces the hydrogen impurity in the sodium to a lower level than the oxygen impurity.

If the original charge of sodium contains calcium as well as oxygen ( $\mathrm{Ca}>4$ ppmw), calcium oxide will be formed in preference to sodium oxide and will be precipitated in the cold trap(l).

other impurities in the sodium are unaffected by the loop operation (except in a negative sense whereby the loop adds impurities). other techniques of purifying sodium include hot traps (solid getters), soluble getters, filtration, settling and centrifuging - see Reference 1 for a discussion of these methods.

\section{SODIUM LOOP DESCRIPTION}

The sodium loop is shown schematically in Figure 3. Basically, the loop consists of the necessary pipes, tanks, valves, pumps, heaters and controls to safely circulate and maintain molten sodium at a temperature of $400^{\circ} \mathrm{C}$. Since molten sodium is a hazardous material, a great deal of attention was devoted to the design of the loop. The loop is located in a remote area (Tech Area III) of Sandia National Laboratories where the consequences of a loop failure are minimized. The loop is under the complete control of a dedicated computer system.

\section{Mechanical}

Refering to Figure 3, the loop has two tanks; a supply tank (Tl) used to fill the loop but not a part of the circulating system and tank T2 which holds the major portion of the circulating sodium. The capacity of the tanks are 68 (257l) and 12 (45.5l) gallons, respectively. The cold trap holds approximately 7 gallons (26l) of sodium. All of the valves and expansion volumes in the loop have trace heaters. The tanks, cold trap, pump, piping and economizer have "calrod" type heaters. These heaters are necessary to get sodium flowing initially. Once flow has been established, the bulk heater supplies most of the energy necessary to raise and maintain the temperature of the circulating sodium at $400^{\circ} \mathrm{C}$. The cold trap is of the forced-air convection type. The cold trap is shown in Figure 4. The economizer, which is in series with the cold trap, is used to assist in heating the cool sodium leaving the cold trap back to $400^{\circ} \mathrm{C}$. It is a single pass counterflow heat exchanger.

\section{Electromagnetic Pump}

An A.C. conduction electromagnetic pump circulates the molten sodium in the loop. The pump operates on the principle of the "lefthand rule." This describes the direction of the force produced on a conductor by a current and a magnetic flux. The principle is illustrated in Figure 5. 


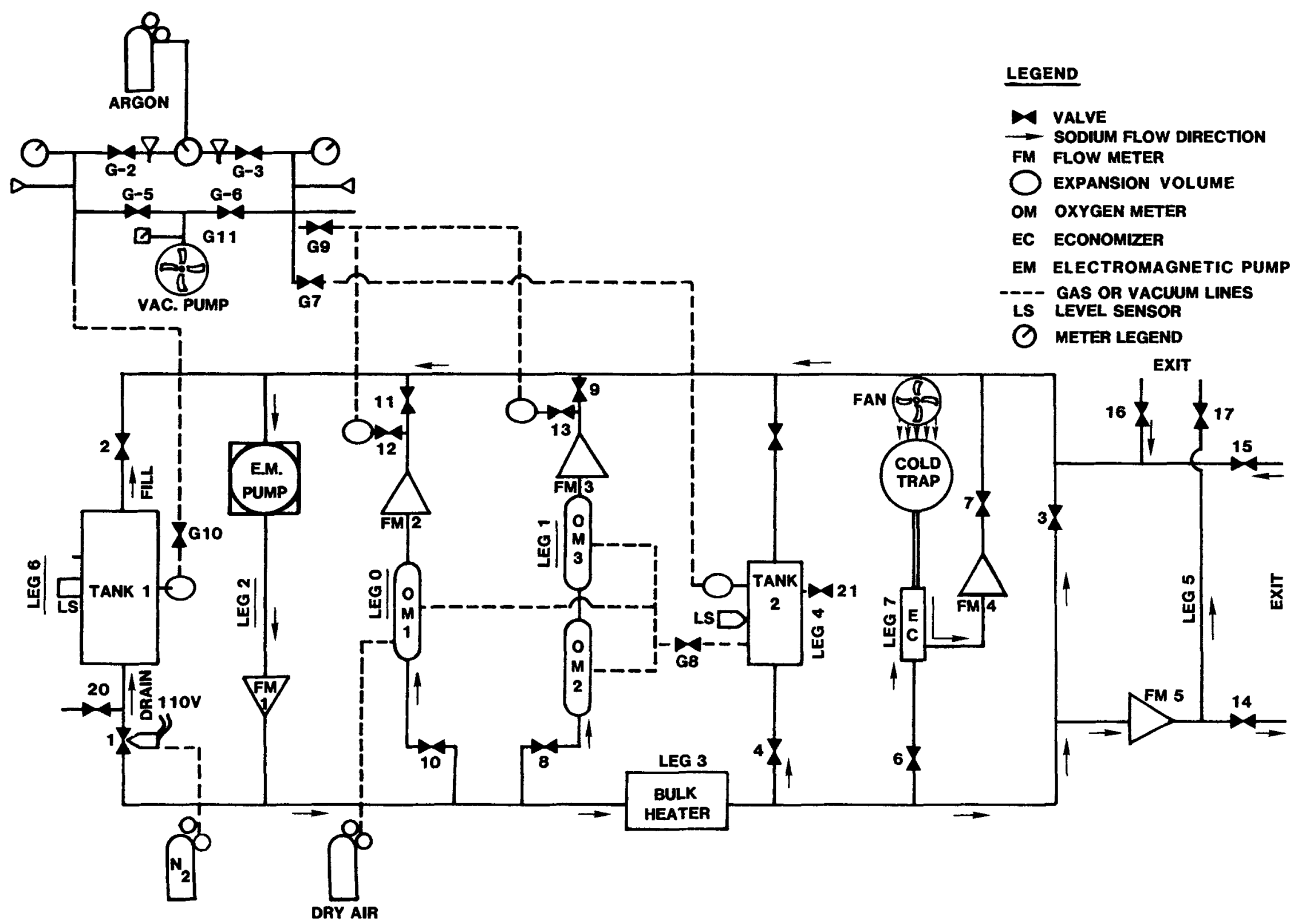

Figure 3. Schematic of Sodium Purification Loop 


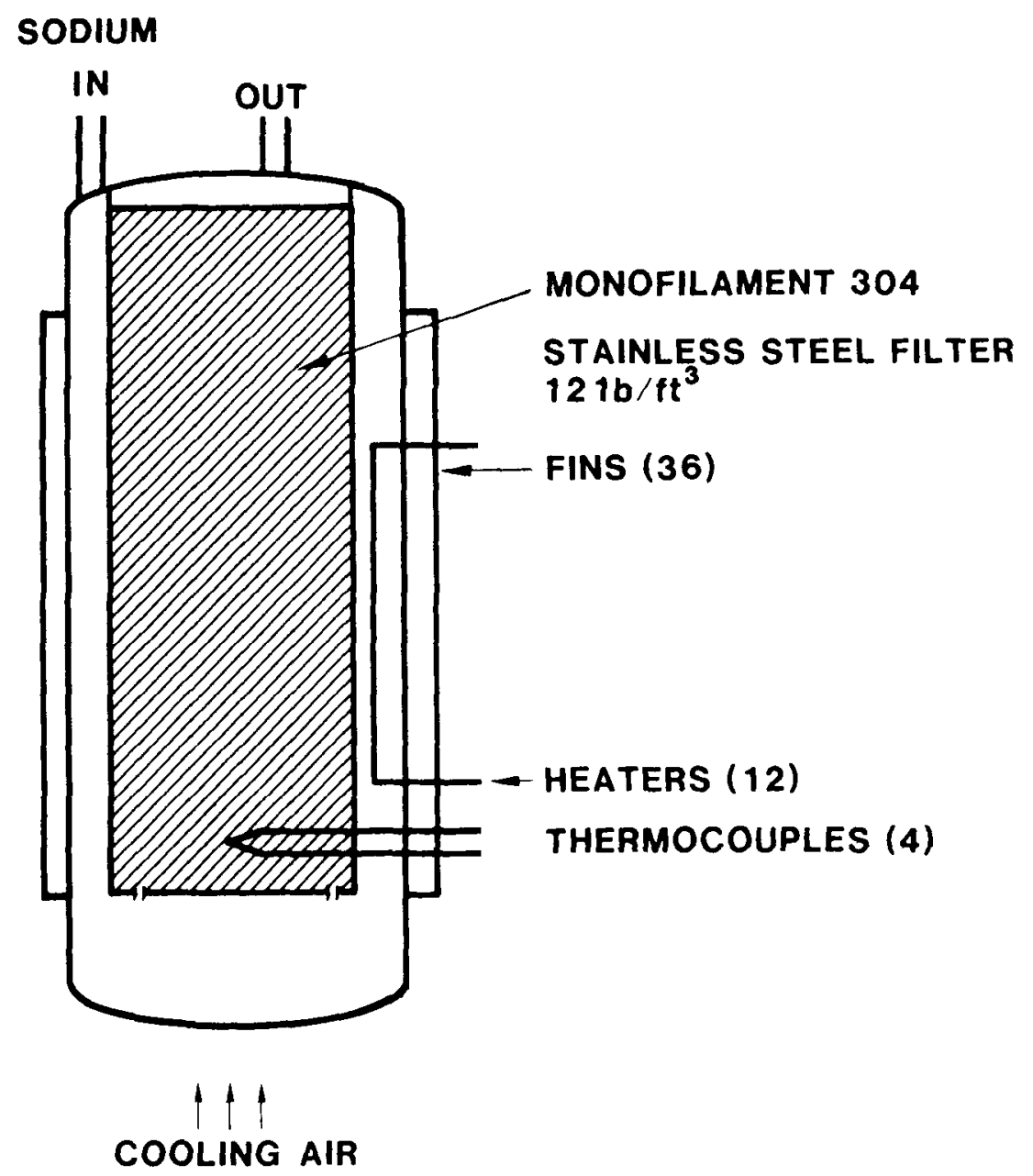

Figure 4. Cold Trap 


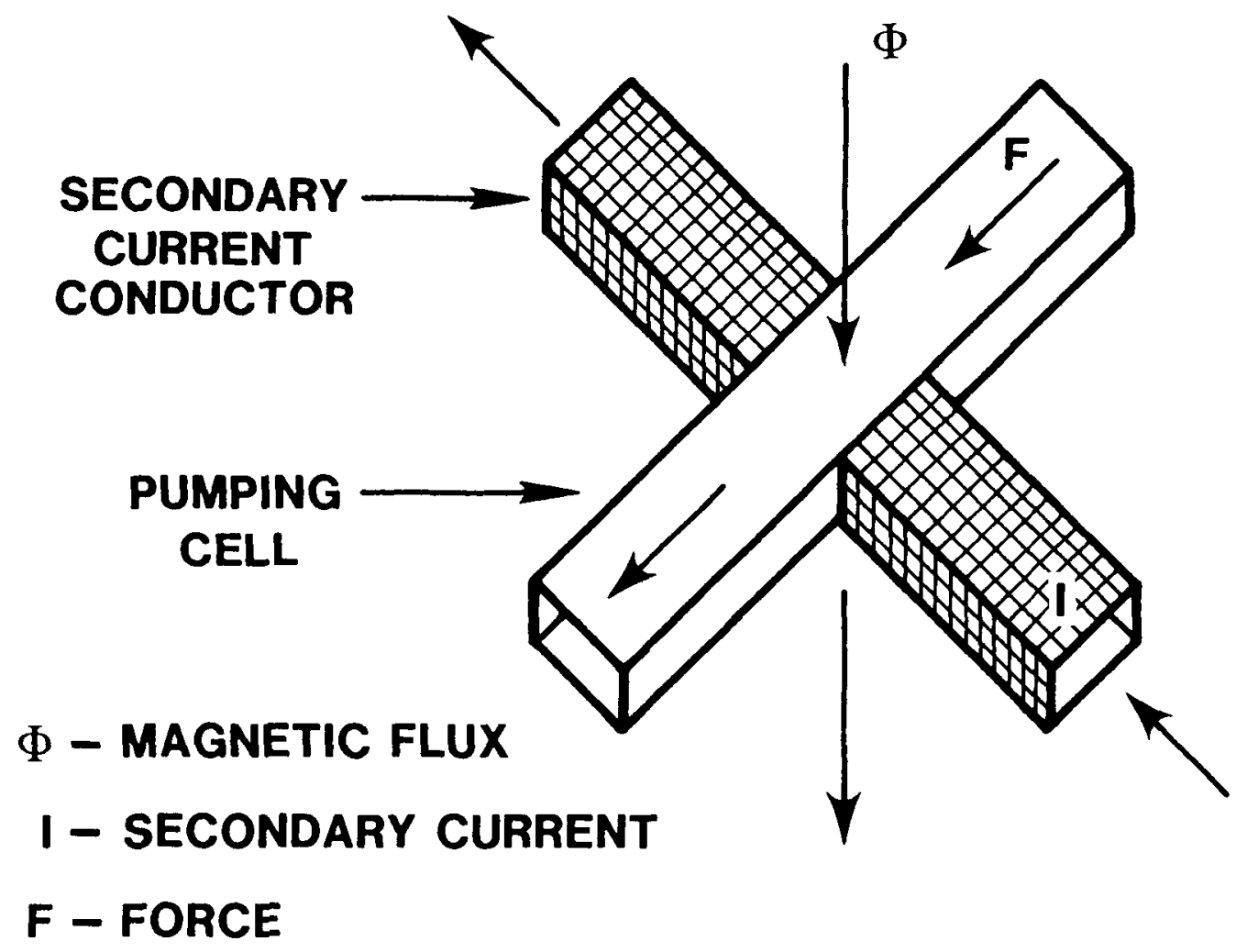

Figure 5. Left-Hand Rule 
In a conduction-type electromagnetic pump, the liquid sodium is a conductor of electricity. When current passes through the pumping section perpendicular to the magnetic field, a force is produced in the liquid sodium within the pumping section that is at right angles to the current and magnetic field. Figure 7 shows how the current and flux are produced in the electromagnetic pump. Two current transformers, connected in series, supply the current in the secondary conductor (bus bars). The current flows through the pumping section wall to the liquid sodium and out the other wall. This forms a continuous current path across one flattened portion. The bus bars are attached to the pumping section using a high temperature braze. The magnetic flux in the pumping section is produced by coils on each leg of two U-shaped laminated magnetic iron cores. The cores are positioned so that the two flattened portions of the pumping section are in the air gaps. At a given voltage input to the pump, there will be a corresponding output of flow and developed head. The performance curve for the pump showing this flow-pressure relationship is shown in Figure 6 .

The electromagnetic pump circulates sodium not only around the loop but also through the experimental apparatus when it is attached to the loop on one of the "exit" legs shown in Figure 3. In this way, contamination in the experimental apparatus may also be removed.

\section{Cover Gas System}

The loop is provided with a vacuum and cover gas system. This system provides for the initial purge from the loop of air and moisture, provides a vacuum to assist in filling the loop with sodium and provides a positive pressure inert gas cover (argon) so that any small leak will not allow air back into the system. Figure 8 is a schematic of the cover gas system.

\section{Valves and Piping}

All parts of the loop exposed to sodium are fabricated of stainless steel. The piping is 304L stainless steel and was chosen for its corrosion resistance and for its good welding characteristics. Each segment, before it was welded into the loop, was cleaned according to the procedure outlined in Table IV. This cleaning process insured that the loop itself introduced as few contaminants as possible into the original charge of sodium.

There are 114 welds on the loop. The welds were made with a tungsten/inert gas, automatic pipe welding machine. Each weld was $x$-rayed for flaws. The loop was tested with a helium leak detector after final assembly.

Bellows type valves are used on the loop. The stems of these valves do not rotate and the stainless steel bellows provides a positive barrier against sodium leakage. See Figure 9. Any attempt to operate a bellows valve when the sodium is still frozen will probably rupture the bellows. 


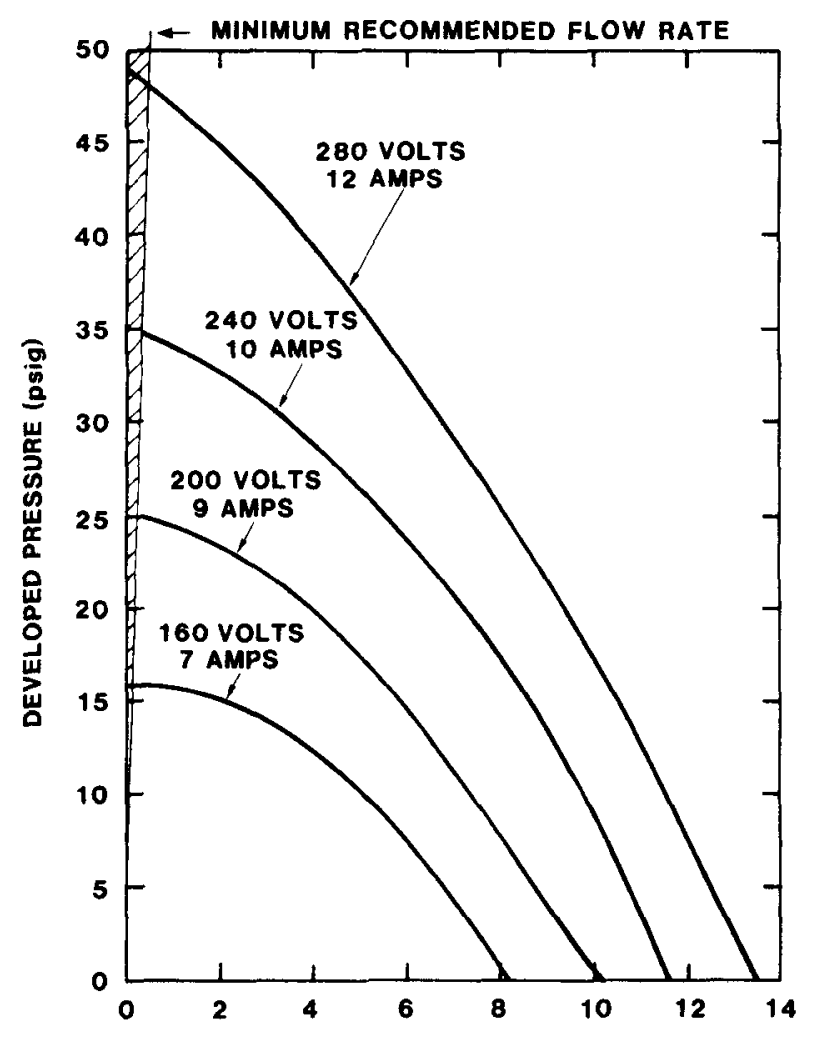

Flow gpm

Figure 6. Electromagnetic Pump

Flow Characteristics 


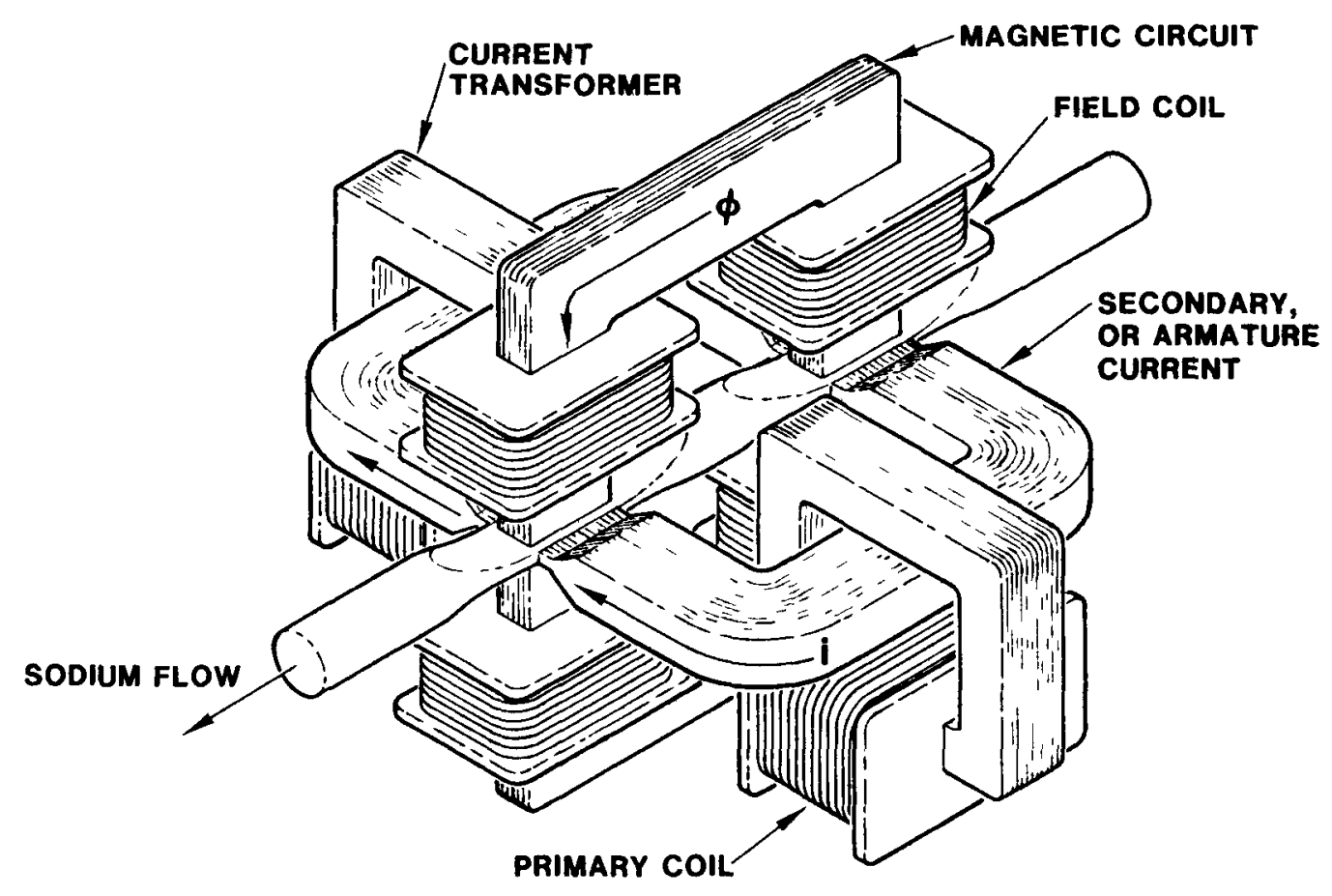

Figure 7. Two-Stage Electromagnetic Pump 


\section{COVER GAS SYSTEM}

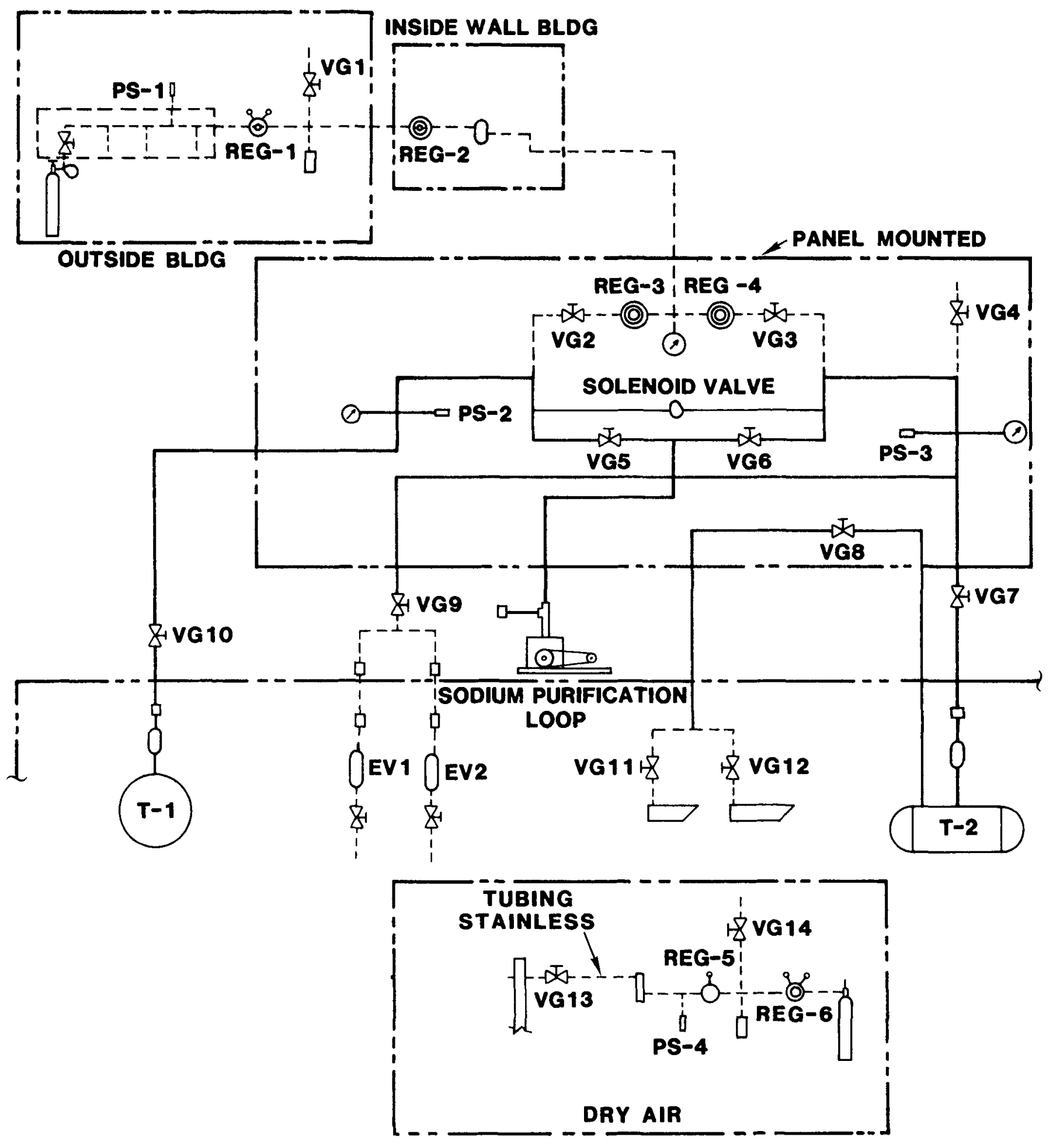

Figure 8. Cover Gas System 


\section{TABLE IV \\ Cleaning Procedure \\ For piping system and components
intended for sodium service}

1. Vapor degrease with Trichloroethylene

2. Caustic electro cleaner (sodium hydroxide)

3. Tap water rinse

4. Rinse in $50 \%$ by volume hydrochloric acid (to remove heavy oxides)

5. Tap water rinse, DI (Deionized water) rinse followed by tap water rinse

6. Rinse in 158 hydrogen peroxide at $125-130^{\circ} \mathrm{F}$

7. Tap water rinse

8. DI water rinse (2 stages)

9. Dry with isopropyl alcohol 


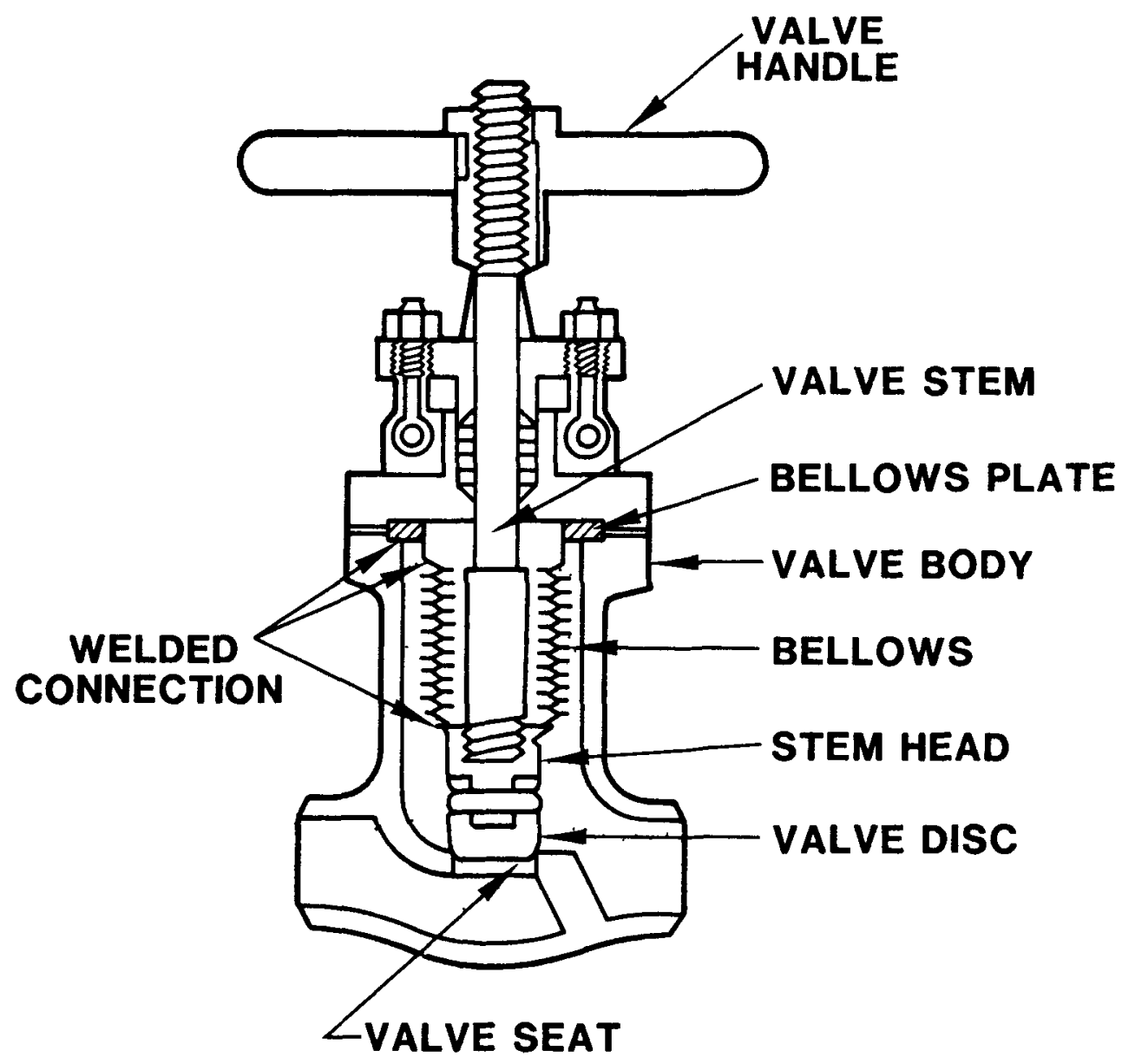

Figure 9. Bellows Valve 
All valves on the loop are manually operated except one. valve number 1 in Figure 3 is an electrically operated pneumatic valve. This valve is located on one corner of the loop that, by design, is the lowest point of the recirculating portion of the loop. When valve number 1 opens, all of the sodium drains back into the storage tank, TI, except for that sodium in the cold trap. Besides draining the loop on normal shutdown, valve number 1 acts as a safety valve when the loop is running unattended by opening on electrical power failure. However, it has been found necessary to circumvent this safety feature on occasion. Thunderstorms are frequent in this area during July and August. Lightning strikes cause power failures that last from a few seconds to as much as half an hour. The power failures cause valve number 1 to open and drain the loop, with the possible loss of several days of cold trapping time. To prevent this from happening, a bypass tube has been placed on valve number 1 that supplies gas pressure to both sides of the actuating diaphram at the same time. The pressure bypass may be used only when the loop operator is present. On unattended operation, the valve is always placed in the mode that will drain the loop on power failure.

\section{Instrumentation}

\section{Magnetic Flowmeters}

The flow of sodium through the various legs of the loop is measured by magnetic flowmeters. These devices act in the reverse sense of the electromagnetic pump. A conductor moving in a magnetic field generates a current in a direction perpendicular to the moving conductor and to the field. Permanent magnets are used for the flowmeters since it is only necessary to produce millivolts for measurement purposes. See Figure 10. The emf generated by the sodium flowing in the meter may be calculated by the equation (5).

$$
\operatorname{emf}(\mathrm{mv})=\frac{\mathrm{QB}(\mathrm{K} 1)(\mathrm{K} 2)(\mathrm{K} 3)}{3162 \mathrm{~d}(\mathrm{~K} 4)}
$$

where

$$
\begin{aligned}
& \mathrm{Q}=\text { flow rate (gpm) } \\
& \mathrm{d}=\text { pipe inside diameter (in.) } \\
& \mathrm{B}=\text { flux density (gauss) } \\
& \mathrm{K} 1=\text { pipe wall shunting factor } \\
& \mathrm{K} 2=\text { end effect factor } \\
& \mathrm{K} 3=\text { magnet temperature factor } \\
& \mathrm{K} 4=\text { pipe expansion factor }
\end{aligned}
$$

$$
K I=\frac{2 d D}{D^{2}+d^{2}+\left((p 1 / p 2)\left(D^{2}-d^{2}\right)\right)}
$$

where

$$
\begin{aligned}
\mathrm{D}= & \text { pipe outside diameter (in.) } \\
\mathrm{p} 1 / \mathrm{p} 2= & \text { ratio of electrical resistivities } \\
& (\mathrm{l}=\text { sodium, } 2 \text { =pipewall) }
\end{aligned}
$$




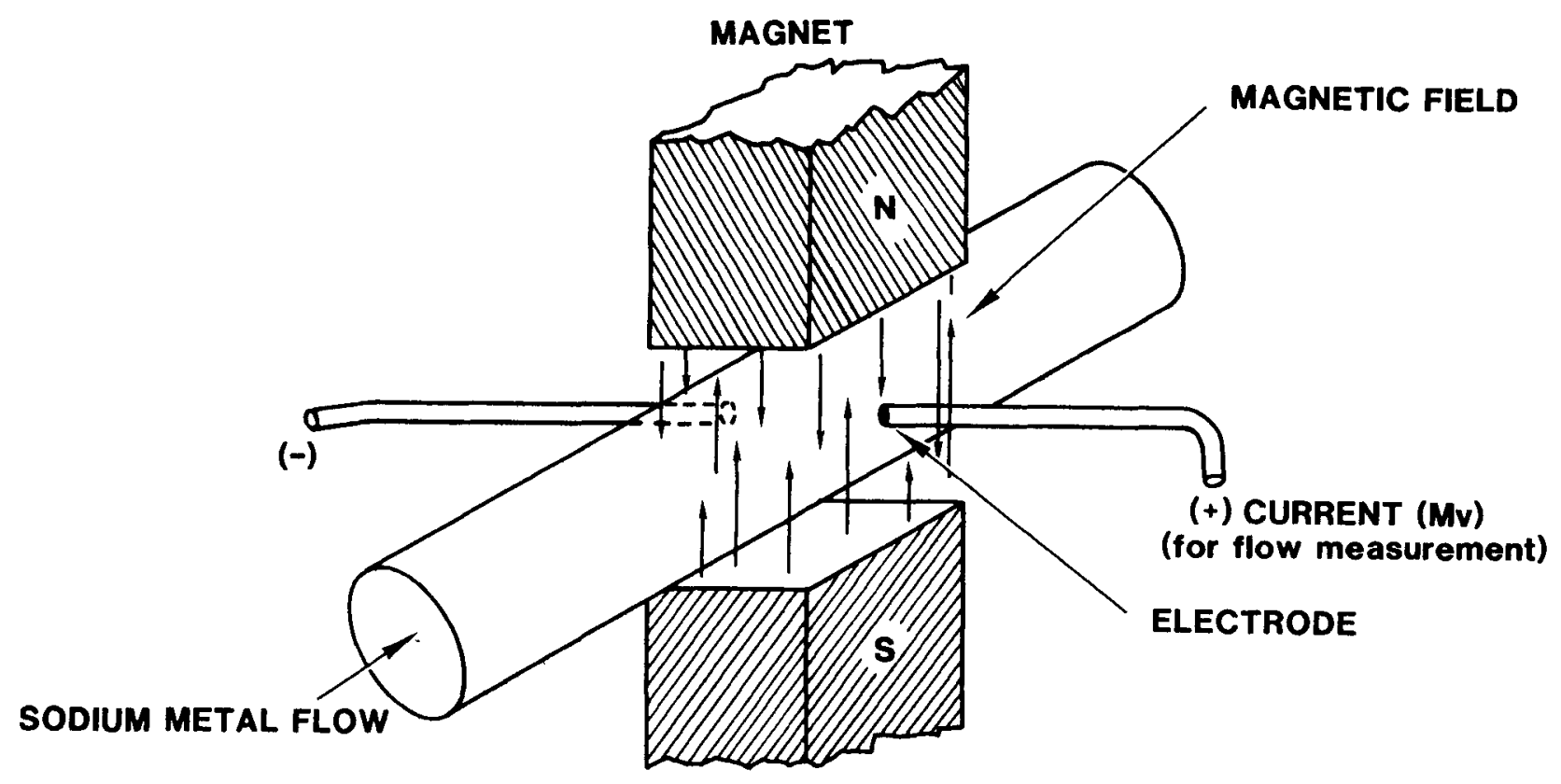

Figure 10. Schematic of Electromagnetic Flowmeter 


$$
\mathrm{K} 4=1+\mathrm{a}\left(\mathrm{T}-\mathrm{T}_{0}\right)
$$

where

$$
\begin{aligned}
& a=\text { coefficient of thermal expansion (pipe) } \\
& \mathrm{T}=\text { temperature }\left({ }^{\circ} \mathrm{F}\right)
\end{aligned}
$$

$\mathrm{K} 2$ and $\mathrm{K} 3$, the end effect and magnetic temperature factors, may be obtained from Figure 11 and 12. The sodium loop has flowmeters for one-half and three-quarter inch diameter pipes. The calculated outputs for these flowmeters are 0.48 and $0.32 \mathrm{mv} / \mathrm{gpm}$, respectively. It is stated in Reference 5 that the difference between calculated and calibrated flow factors for these meters is within a few percent entirely satisfactory for our purposes of dividing the flow of sodium between the various parallel legs of the loop.

\section{Thermocouples}

One hundred twenty-three thermocouples monitor temperatures around the loop. Fifty-eight connect to the computer. Forty-two connect to the manual control system and 23 are backup. The couples are type $\mathrm{J}$, iron-constantan. Another 14 thermocouples are available on the two exit legs of the loop where experiments to be filled would be located. On thick sections such as valve bodies, the thermocouples were spot welded directly to the valve body. Rather than weld thermocouples directly to the piping, a special thermocouple well was designed. Drawings T72443 to T72445 (Fig. 13) give details of the well. The location of each thermocouple is shown on drawing T73298 (Fig. 14). A complete list of drawings for the loop is given in Appendix D. Any drawing referenced in the body of this report is also included in Appendix $D$.

\section{Oxygen Meters}

Three oxygen meters are installed on the sodium loop. Meters are manufactured by either General Electric Co. or by Westinghouse. The meters are similar in design. A solid electrolyte material separates two electrodes. The solid electrolyte is yttria doped thoria. One electrode is the molten sodium. For the reference electrode, GE uses a solid mixture of a metal and its oxide (gallium, indium or tin) whereas WE uses a gas. In the WE meter, the thoria is platinum coated on the gas electrode side. The gas electrode is normally air, but may have any oxygen concentration between 1008 to below 10 ppm as long as the concentration is known and kept constant. Figure 15 shows a schematic of the WE cell. The solid electrolyte, thoria, has the ability to conduct oxygen ions by means of lattice vacancies. Since the oxygen activity in the sodium is so low, there is a spontaneous tendency in the cell for oxygen ions to migrate from the reference electrode to the sodium electrode. This migration results in the creation of an electrochemical concentration cell with a corresponding electromotive force (voltage). Measurement of this voltage gives an indication of the oxygen concentration in the molten sodium. The voltage is best measured by a differential electrostatic meter so that 


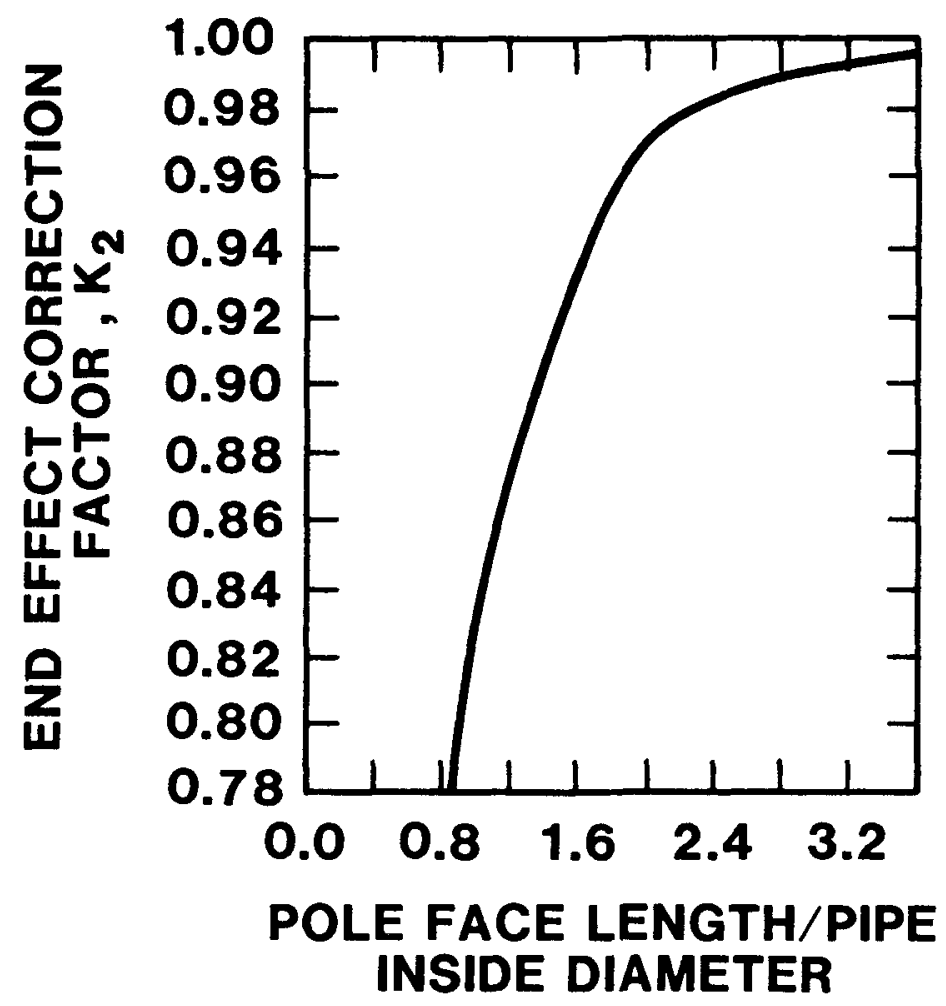

Figure 11. Flowmeter End Effect

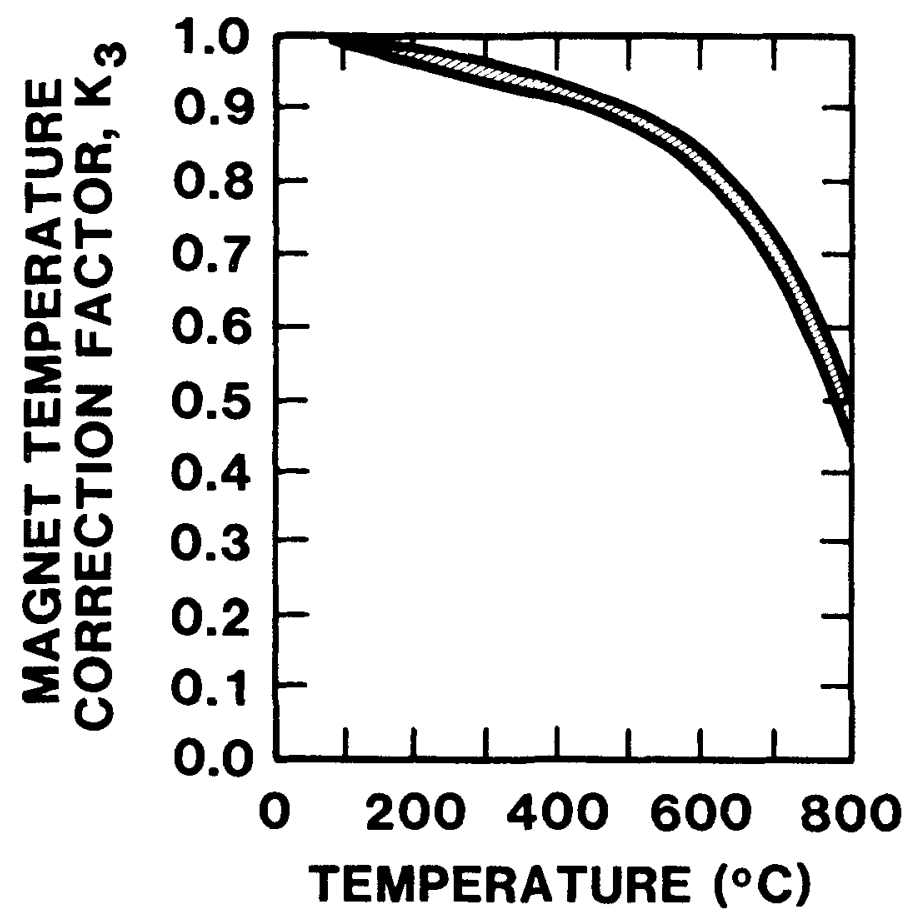

Figure 12. Flowmeter Temperature Correction Factor 
oxygen ions are not driven to the sodium. The expected voltage output for the meters are as follows:

General Electric Meter

$$
\text { emf }=0.269+\frac{160}{T} \text { volts (sensor at } 773 \mathrm{~K} \text { ) }
$$

where $T$ is the cold trap temperature in degrees $K$

The temperature coefficient of the meter is given as $0.51 \mathrm{mv} / \mathrm{K}$.

The Sandia loop operating at $400^{\circ} \mathrm{C}(673 \mathrm{~K})$ with a cold trap temperature of $120^{\circ} \mathrm{C}(393 \mathrm{~K})$ would give an output of about $675 \mathrm{mv}$.

$$
\begin{gathered}
\text { Westinghouse Meter } \\
\text { emf }=1.843-0.064 \mathrm{Log} C \text { volts (sensor at } 744 \mathrm{~K} \text { ) }
\end{gathered}
$$

where $C$ is the oxygen concentration in ppm.

The temperature coefficient of the meter is given by the manufacturer as $-0.068-0.055 \mathrm{Log} \mathrm{C} \mathrm{mv} /{ }^{\circ} \mathrm{F}$.

The Sandia loop operating at $400^{\circ} \mathrm{C}(673 \mathrm{~K})$ with a cold trap temperature of $120^{\circ} \mathrm{C}(393 \mathrm{~K})$ would give an output of about $1.78 \mathrm{v}$.

Figure 16 shows the averaged output of several meters from both manufacturers.

Calibration of these oxygen meters is difficult. One technique is to add a measured quantity of sodium hydroxide pellets to the sodium in the loop through a gate valve (Valve 21 , Figure 3 ). This is a hazardous undertaking and was only performed at loop start-up. Typically, the oxygen concentration in the sodium is assumed to follow the equation of Noden (eq. 1). Experience has shown this to be a good assumption. The oxygen meters have been used as indicators only. During an experiment purification and filling session, the oxygen meters are monitored until they come to an equalibrium value, at which point the oxygen concentration is taken as the value associated with cold trap temperature.

The major problem with both meters is thermal shock sensitivity. The thoria solid electrolyte is extremely sensitive to cracking if the temperature change rate exceeds $2^{\circ} \mathrm{C} / \mathrm{min}$. This rate has been exceeded on numerous occasions. Power failure when the loop is unattended has been the main reason. The loop automatically drains on an unattended power failure, exposing the oxygen meters to fast cooling rates. Consequently, after several years of operation, only one of the meters is functional. 


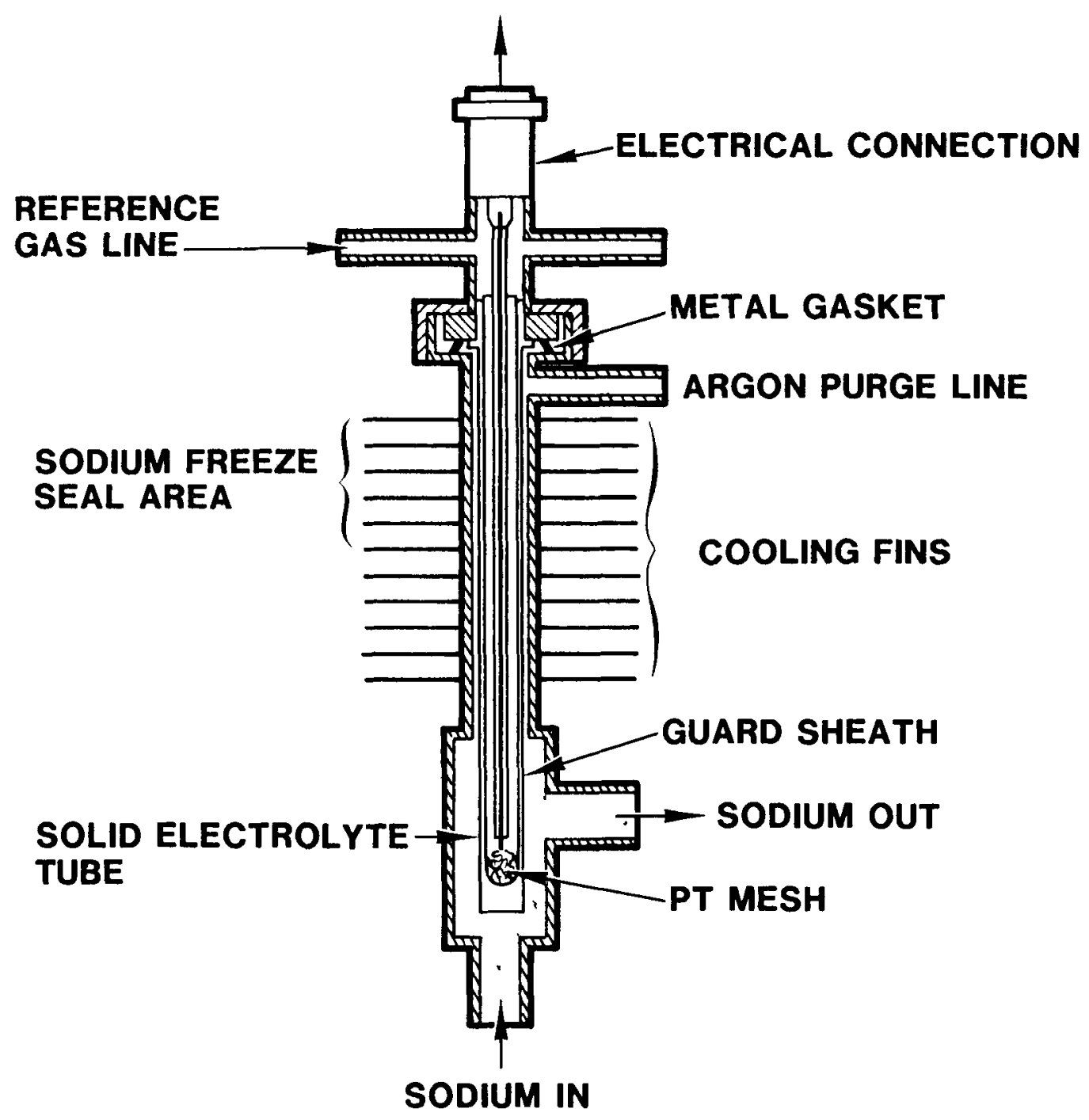

Figure 15. Schematic of Westınghouse Oxygen Meter 


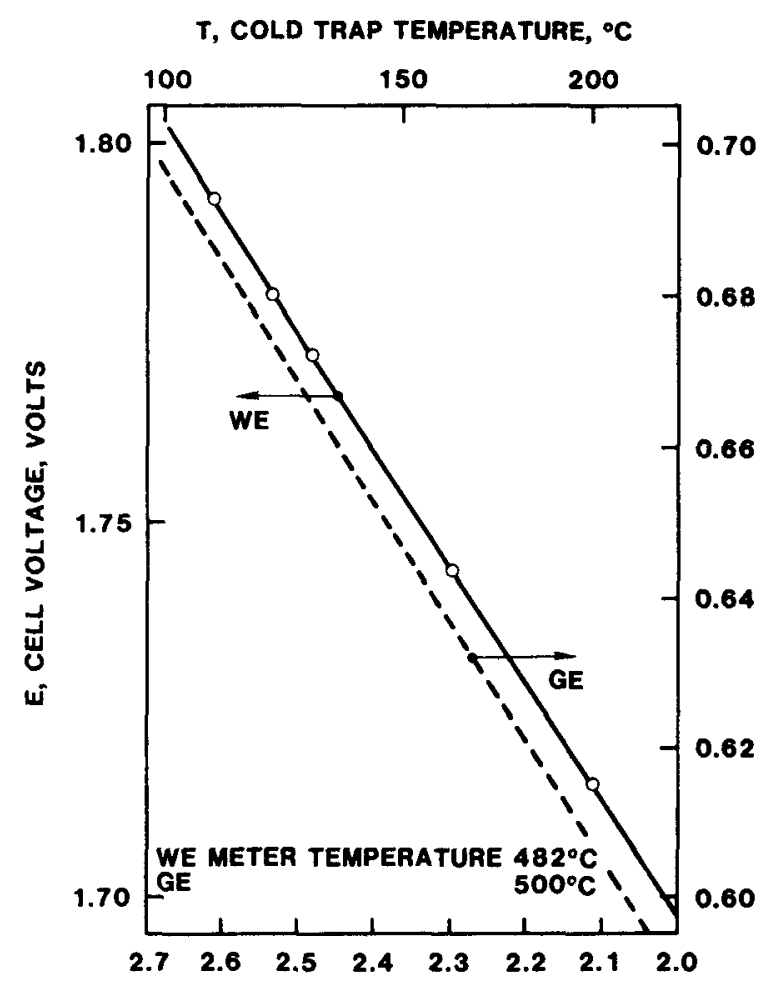

$1000 / T$, RECIPROCAL COLD TRAP TEMPERATURE, ${ }^{\circ} \mathrm{K}^{-1}$

Figure 16. Oxygen Meter Output 


\section{Level Detection}

Normal operation of the sodium loop requires that the amount of sodium in the storage tank, $T l$, and in the circulation tank, $T 2$, be known. This is accomplished with two types of level detectors and a knowledge of the volumes of the tanks.

A multipoint level detector was designed and built for tank T2 on the loop. This detector is shown schematically in Figure 17 . Seven stainless steel rods extend down into the tank through a flange. Each rod is electrically insulated from all other rods and also from the tank. Each rod extends to a different level in the tank. A light emitting diode is placed in series in the electrical circuit of each rod. A 5 volt source is imposed on each rod with the return circuit being the tank. As sodium raises in the tank, it contacts the lowest positioned rod and that diode lights. As sodium fills the tank, each diode in turn lights. Knowing the position of the rod tips above the tank bottom gives an indication of the level of the sodium in the tank and, consequently, the volume of the sodium. Tank elevation versus volume is given in Table $V$. A major problem with the multipoint level probe is that sodium vapor forms a frost. This frost collects on the rods making the location of the tip uncertain and sometimes shorts one rod to another. Gently tapping the probe flange will occasionally dislodge the frost. A second technique for measuring sodium in Tanks $\mathrm{T} 1$ and $\mathrm{T} 2$ is a "bubbling" manometer.

A schematic of a bubble manometer is shown in Figure 18. The manometer measures the difference in pressure between the bottom of the tank and the liquid sodium surface. A tube is inserted through the top of the tank with its opening at the bottom of the tank. An inert gas supply is conected to the tube. With sodium in the tank, the gas pressure is increased until approximately one bubble per second is generated. Bubbles in the tank cannot be seen so a bubble chamber is placed in the gas line. The pressure side of the manometer (the manometer well) is connected to the gas line while the top of the manometer is connected to the vapor space above the sodium. various valves, checkvalves and vents are required to insure that the sodium never comes into contact with the liquid in the manometer or in the bubble chamber. The manometer scales are calibrated in gallons of sodium in the tank.

\section{Power and Control}

\section{Computer}

The entire sodium loop is under the control of a dedicated computer system. The loop operates for hundreds of hours at equilibrium without human intervention. The computer interrogates the various parts of the system, makes comparisons, decisions and issues commands or alarms. Figure 19 is a schematic of the system instrumentation, controls and alarms. 


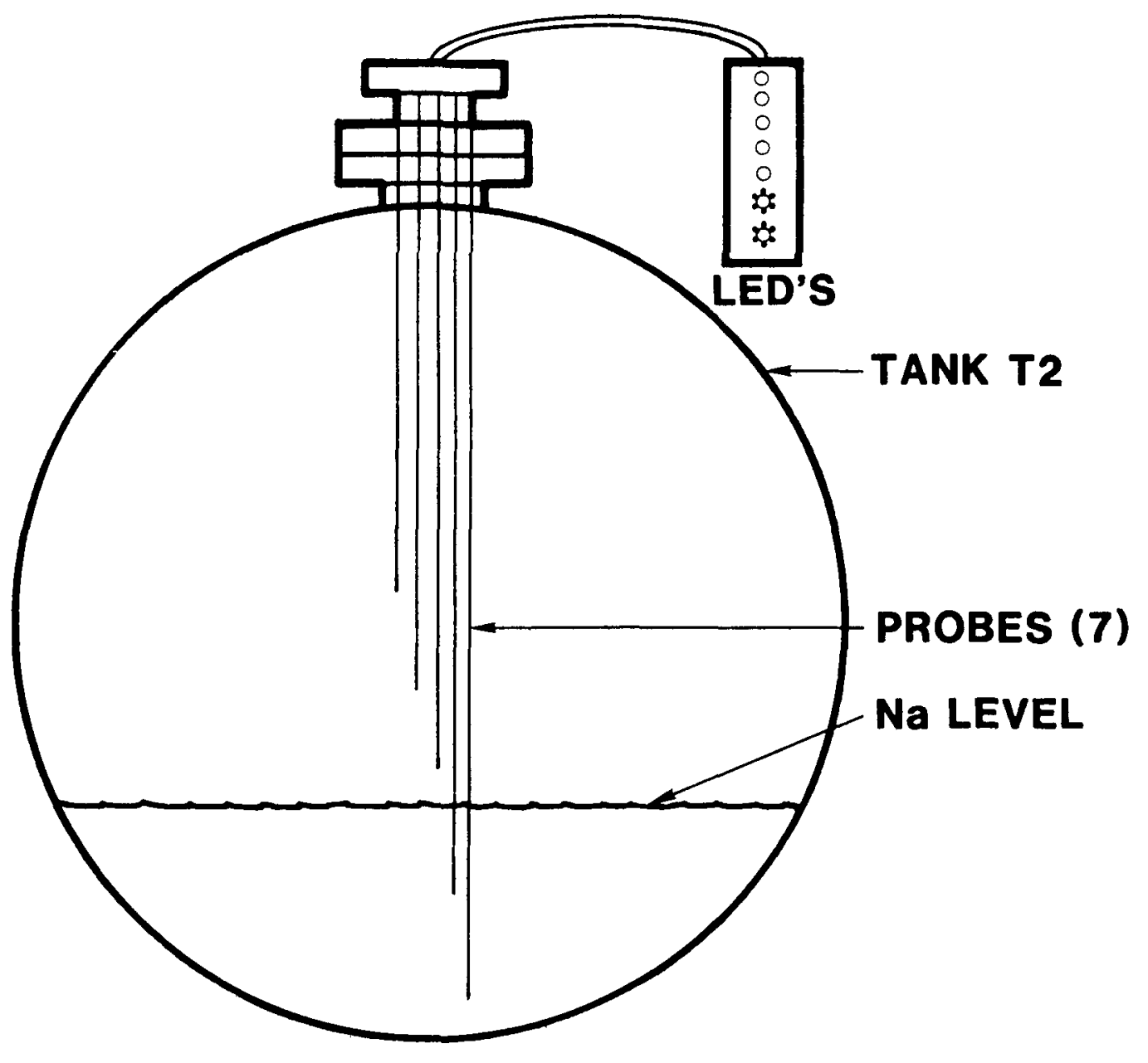

Figure 17. Probe Level Detector Schematic 
TABLE V

TANK TI VOLUME

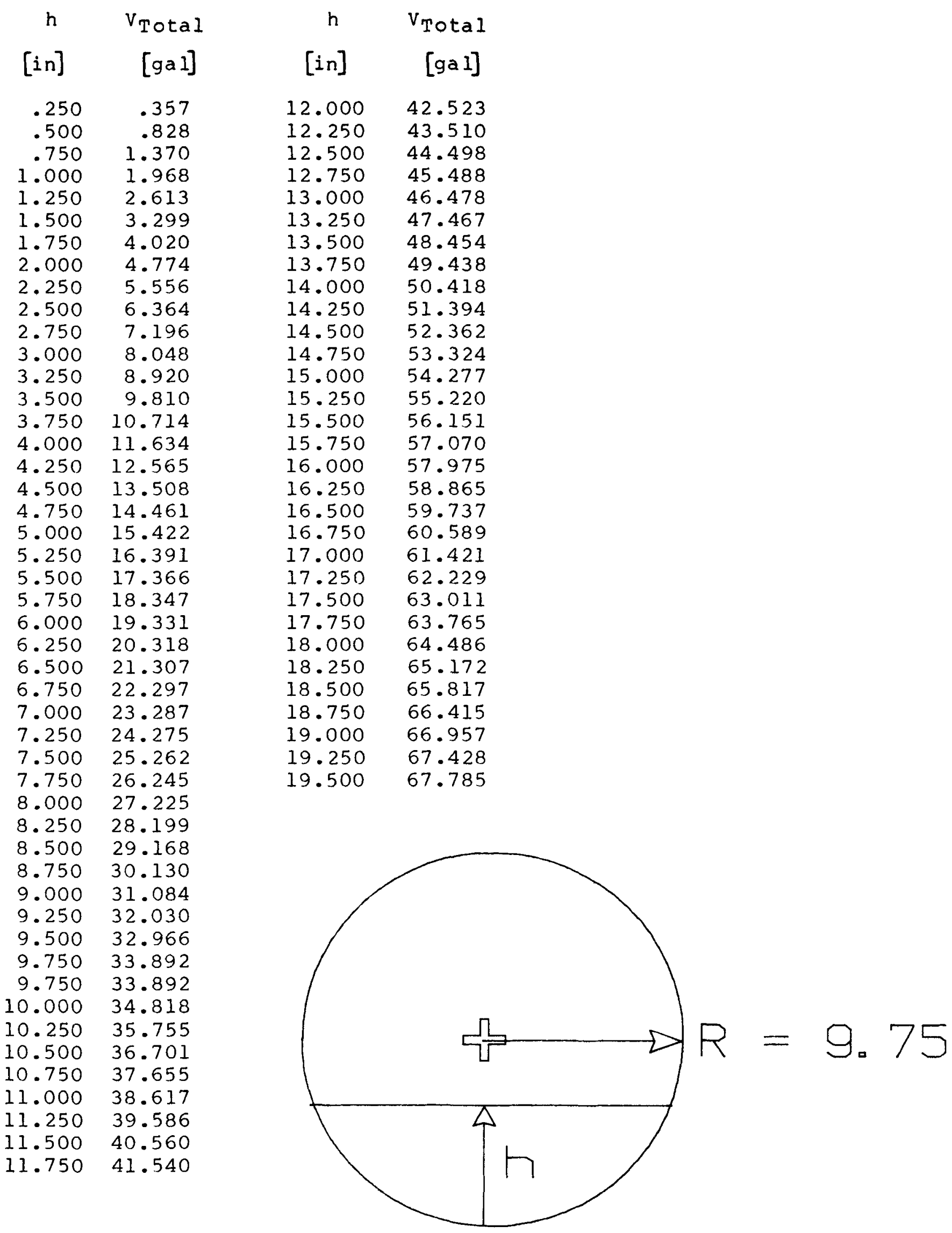


TABLE V

TANK T2 VOLUME

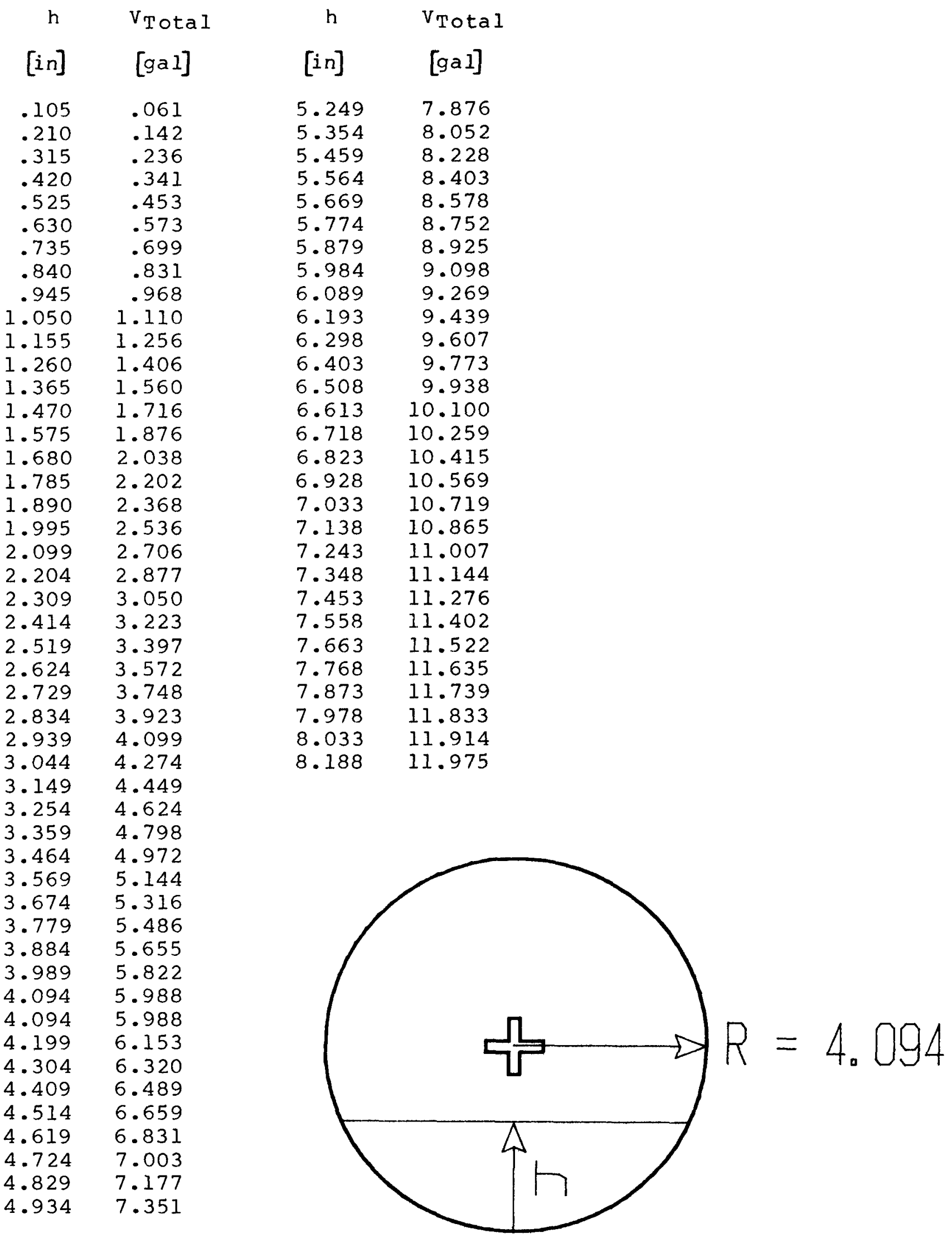




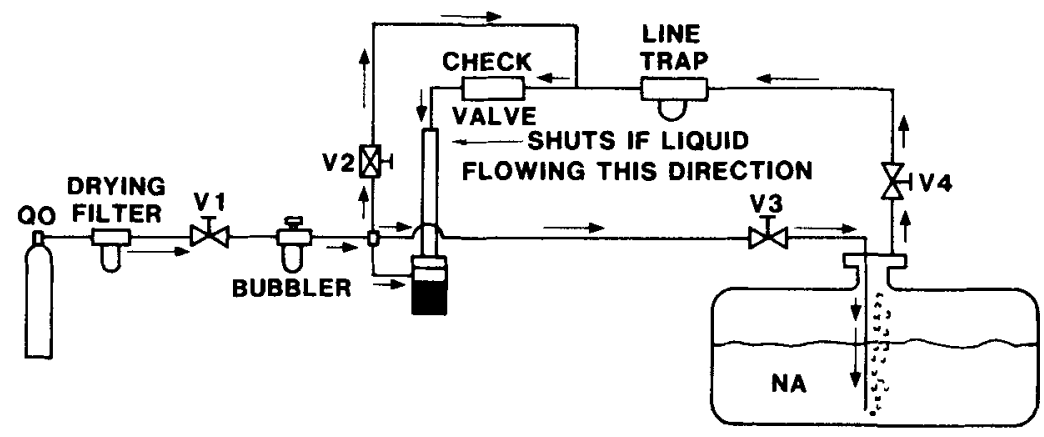

Figure 18. Bubble Manometer Level

Detector Schematic 


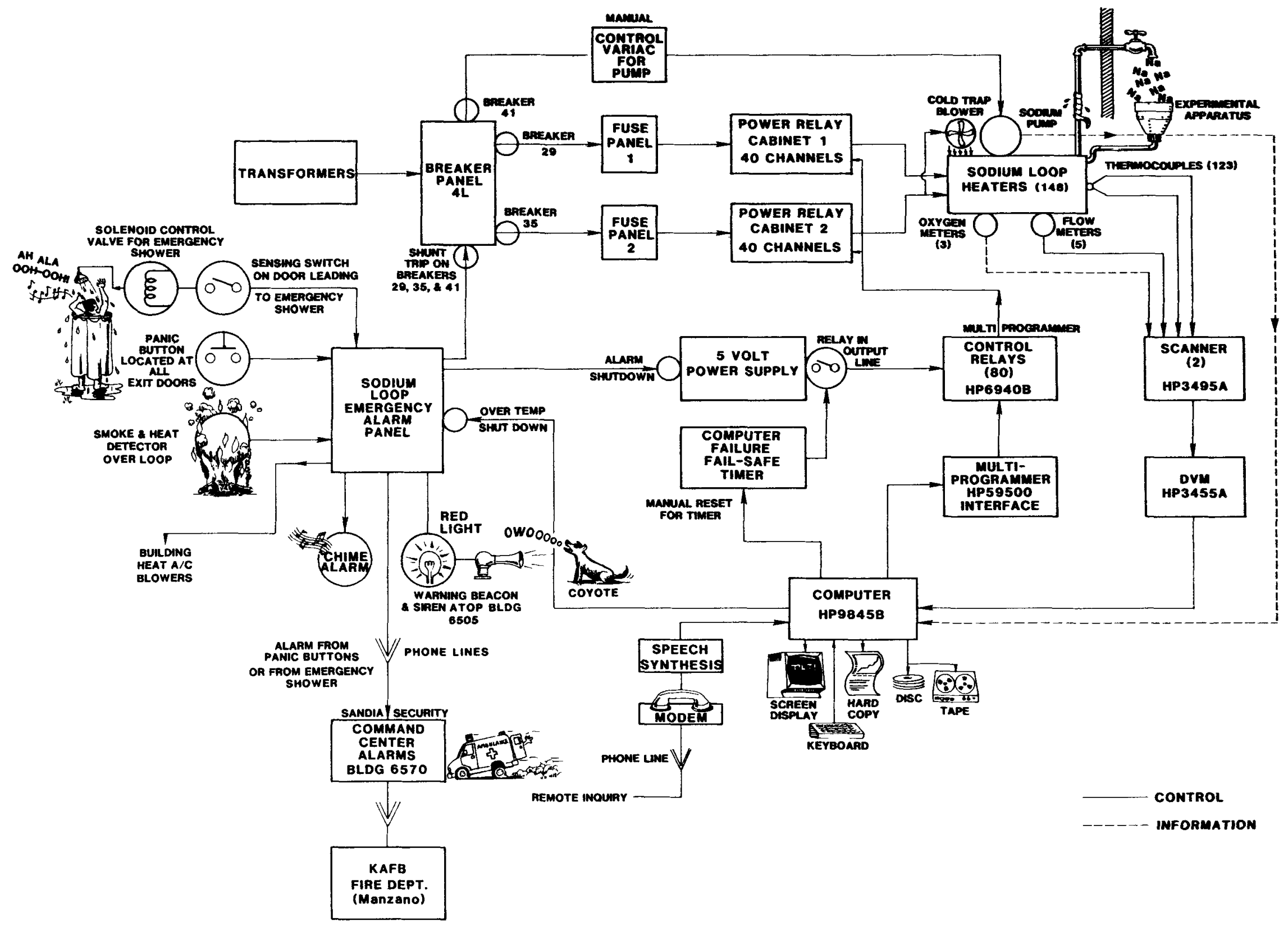

Figure 19. Sodium Loop Instrumentation, Alarms and Control Schematic 
Because sodium is a hazardous material, numerous failure modes must be anticipated and provisions made to minimize the consequences of these failures. In the event of a sodium leak and fire, heat and smoke detectors over the loop will alarm. Panic buttons at each outside door to the building scram the loop--draining the sodium back into the storage tank, kill all power to the loop and to the building heating and ventilating system--and send an alarm to the security center. Opening the door to the emergency shower sounds an alarm, turns on the shower and automatically calls an ambulance. In case the computer itself fails, a reset timer and relay turns off power to the loop. The timer is set to countdown from 5 minutes and to open the control power relay at that time. The computer must reset this timer within the 5 minutes if the loop is to continue to operate. Actually, the computer goes through a complete cycle about once every 30 seconds and resets the timer every third cycle. The loop also shuts down if the computer senses temperatures that are over a predetermined set point. This set point is different from the control set point. The actual control functions are:

1. Heater on-off (time on is variable)

2. Cold trap fan on-off

3. E.M. Pump on-off

4. Vacuum pump on-off

5. Drain valve open-close

6. Entire system on-off

The system is divided into control zones - called legs in Figure 3. The heaters in any leg operate independently. The length of time that a heater is on depends on how far the heater temperature is from the control temperature set point. The temperature of the entire system, a leg or an individual heater may be set with a single command. The exception to this is that the oxygen meter legs and the cold trap leg will not respond to a command to LOWER the temperature of the entire system. This is a safety feature to protect the oxygen meters and to keep from inadvertantly freezing the cold trap. All other control functions are simple on-off. The flow of the electromagnetic pump is manually adjustable. A typical control circuit is shown in Figure 20. As shown in this figure, it is possible to control various functions manually. Any given heater may be turned on or off by setting a switch on the control panel. The same is true for the other functions. Wrapable heaters were used on the valves and expansion volumes and "cal-rod" type heaters on the piping and tanks. The valve heaters are one-half inch wide and of various lengths. They are rated at 48 watts per foot. The cal-rod heaters are tubular with inconel sheaths and magnesium oxide insulation. Heaters were rated at either 30 watts per inch or 22 watts per inch and 240 volts. All heaters except the pump heaters are operated at 120 volts to increase heater life. The heater switches are three position type. In the up position, the heater is under computer control, down it is manually on, and in the middle position it is off. The middle position is also a test position--if the heater is electrically good, the pilot light is off, if not, the pilot light glows softly (less brightly than when the heater is on). 


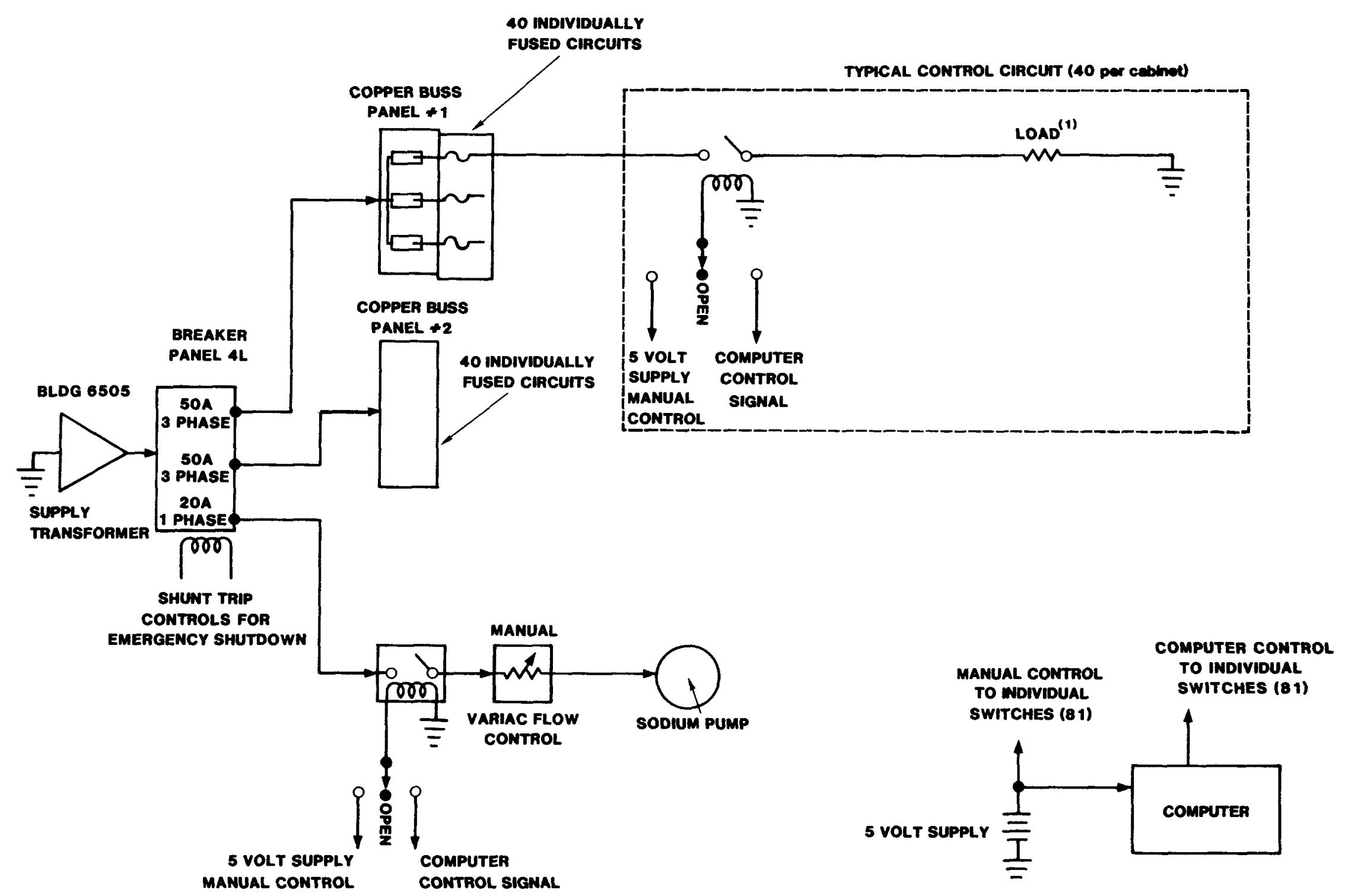

(1) LOAD MAY BE A HEATER, COLD TRAP FAN, SODUM DAAN VALVE DR VACUUM PUMP 


\section{Control Description}

The computer control and data acquisition system consists of the following:

1. Minicomputer

2. Multiprogramer

3. Interface Item 1 to Item 2

4. Scanners (2)

5. Digital voltmeter

6. Power conditioner

7. Electrometers (2)

8. Disc drive for Item 1
HP $9845 B$ *

HP $6940 \mathrm{~B}$

HP 59500

HP 3495A

HP $3455 \mathrm{~A}$

Elgar $6000 \mathrm{~B}$

Keithly 642

HP $9895 \mathrm{~A}$

${ }^{\star} \mathrm{HP}=$ Hewlett Packard

Electrical connections for the computer control and data acquisition system are shown in Table VI. The first channel on each scanner card is a reference junction for the thermocouples on that card (i.e., 0 , $20,40,60)$. Data can be acquired on paper, magnetic tape and disc. The computer program contains a plotting routine so that the data may be plotted as a function of time or some other variable. During normal operations, the results of each computer scan are shown on the screen. The screen display for one such scan is shown in Figure 21. After the date and time line, the channel number is shown in column one. There are three channels per line so the next channel number listed is Channel 4. Next, is a description of where that thermocouple is located. VIO stands for Valve Number 10. The next column gives the temperature for that channel and the fourth column the temperature deviation from the set point. A negative value means that the temperature shown is that many degrees below the set point. The above information is repeated for each channel. At the bottom of the screen display is a line of other than temperature information. The first five are the output of flowmeters in the described legs and the last three are the output of the oxygen meters. Several other lines of information may appear after the ones shown to include warnings of over temperatures, the fact that the fail-safe relay has been reset, or that data record number such-and-such was recorded on the disc or tape. Another form of data display is available. Looking at Figure 21 it is obvious that the operator would have to be close to the screen in order to read any values. The operator may select a display that he can see from anywhere in the control room. In this mode, the operator selects five channels that are of particular interest to him and by use of the "big on" command these five channels and the five flowmeter channels are displayed in large print on the computer screen. A display of this type is shown in Figure 22. Channels 16 , 18, 44,45 and 70 are shown with their corresponding temperatures while the five flowmeters show essentially zero flow. A listing of the computer control code is enclosed on microfiche on the inside back cover of this report. 
TABLE VI

Sodium Purification Loop

Thermocouple/Heater Connections

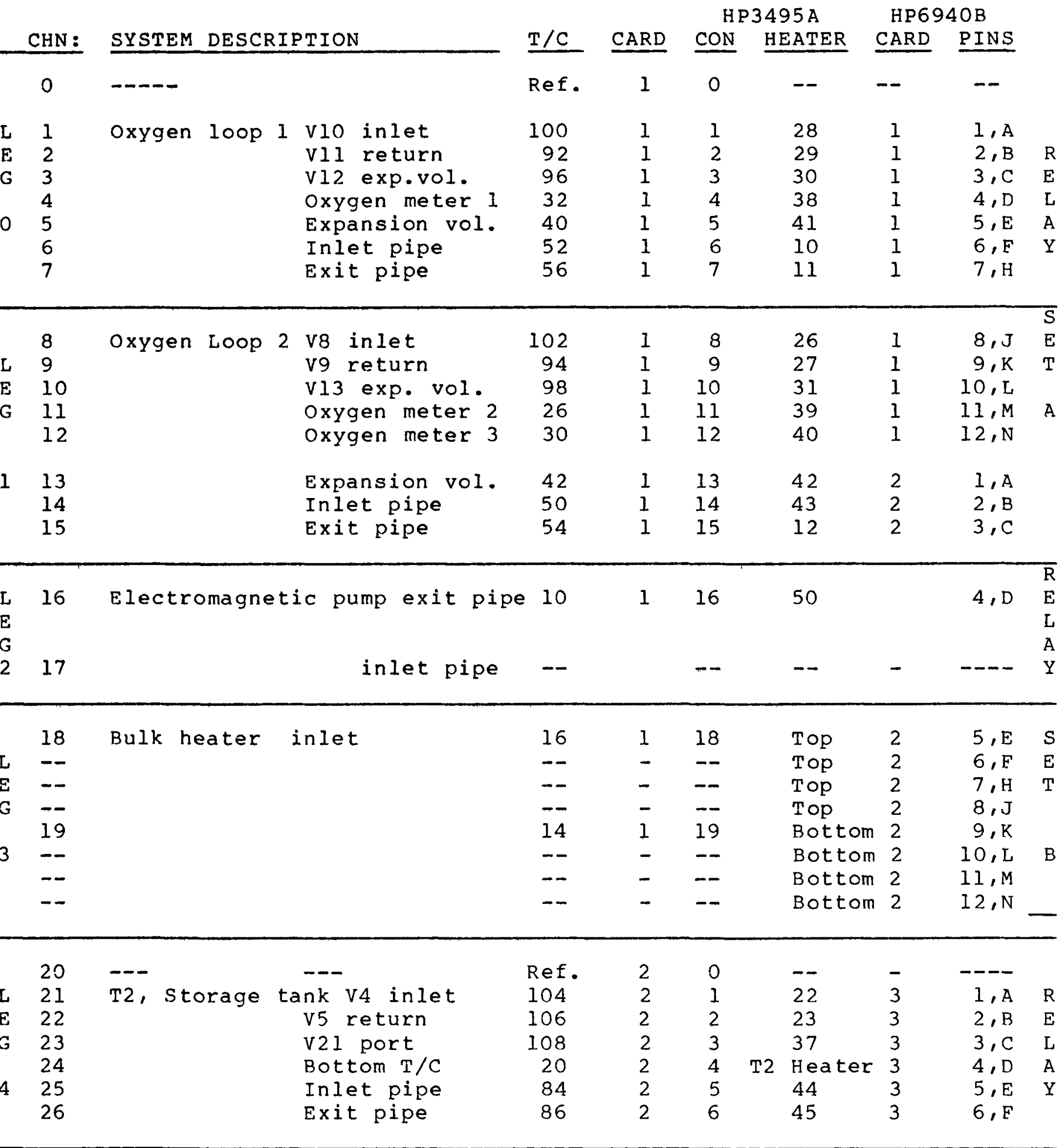


TABLE VI Cont.

CHN: SYSTEM DESCRIPTION

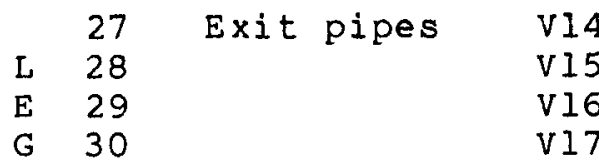

$5 \quad 32$
Exit pipe V15-V16
HP 3495A T/C CARD CON HEATER CARD PINS

122

118

116

120

78

$\begin{array}{rr}2 & 7 \\ 2 & 8 \\ 2 & 9 \\ 2 & 10 \\ 2 & 11 \\ 2 & 12\end{array}$

\section{2}

33

34

35

17
3

3

3

3

3
$7, \mathrm{H} \quad \mathrm{S}$ $8, J \quad E$ $9, \mathrm{~K} \quad \mathrm{~T}$ $10, \mathrm{~L}$ $11, M \quad C$ $12, \mathrm{~N}$

\begin{tabular}{|c|c|c|c|c|c|c|c|c|c|c|}
\hline $\begin{array}{l}\text { L } \\
E \\
G\end{array}$ & $\begin{array}{l}33 \\
34 \\
35 \\
36 \\
37 \\
38 \\
-- \\
39 \\
-- \\
-- \\
-- \\
-- \\
--\end{array}$ & Tl, Storage & $\begin{array}{l}\text { tank Vl inlet } \\
\text { V2 return } \\
\text { V20 port } \\
\text { Rt. end cap } \\
\mathrm{Lt} \text {. end cap } \\
\text { Top } \mathrm{T} / \mathrm{LC} \\
\text { Bottom } \mathrm{T} / \mathrm{C}\end{array}$ & $\begin{array}{r}124 \\
90 \\
88 \\
2 \\
8 \\
6 \\
-- \\
4 \\
-- \\
-- \\
-- \\
-- \\
--\end{array}$ & $\begin{array}{l}2 \\
2 \\
2 \\
2 \\
2 \\
2 \\
- \\
2 \\
- \\
- \\
- \\
-\end{array}$ & $\begin{array}{l}13 \\
14 \\
15 \\
16 \\
17 \\
18 \\
-- \\
19 \\
-- \\
-- \\
-- \\
-- \\
--\end{array}$ & $\begin{array}{c}19 \\
20 \\
36 \\
\text { Tl-side } \\
-- \\
\text { Tl-top } \\
\text { Tl-top } \\
\text { Tl-Bot-Rt } \\
\text { Tl-Bot-Rt } \\
\text { Tl-Bot-Lt } \\
\text { Tl-Bot-Lt } \\
\text { Tl-Bot-Ctr } \\
\text { Tl-Bot-Ctr }\end{array}$ & $\begin{array}{l}4 \\
4 \\
4 \\
4 \\
4 \\
4 \\
4 \\
4 \\
4 \\
4 \\
4 \\
4 \\
4\end{array}$ & $\begin{array}{r}1, \mathrm{~A} \\
2, \mathrm{~B} \\
3, \mathrm{C} \\
4, \mathrm{D} \\
-2,- \\
5, \mathrm{E} \\
6, \mathrm{~F} \\
7, \mathrm{H} \\
8, \mathrm{~J} \\
9, \mathrm{~K} \\
10, \mathrm{~L} \\
11, \mathrm{M} \\
12, \mathrm{~N}\end{array}$ & $\begin{array}{l}R \\
E \\
L \\
A \\
Y\end{array}$ \\
\hline $\begin{array}{l}\mathrm{L} \\
\mathrm{E} \\
\mathrm{G}\end{array}$ & $\begin{array}{l}40 \\
41 \\
42 \\
43 \\
44 \\
45 \\
46 \\
47 \\
48 \\
49\end{array}$ & $\begin{array}{l}\text { Tl, Storage } \\
\text { Cold trap }\end{array}$ & $\begin{array}{l}\text { tank pipe } \\
\text { V6 inlet } \\
\text { V7 return } \\
\text { Trap T/C } 1 \\
\text { Trap T/C } 2 \\
\text { Inlet pipe } \\
\text { Transition pipe } \\
\text { Recovery pipe } \\
\text { Return pipe }\end{array}$ & $\begin{array}{r}\text { Ref. } \\
82 \\
110 \\
114 \\
126 \\
129 \\
72 \\
70 \\
76 \\
80\end{array}$ & $\begin{array}{l}3 \\
3 \\
3 \\
3 \\
3 \\
3 \\
3 \\
3 \\
3 \\
3\end{array}$ & $\begin{array}{l}0 \\
1 \\
2 \\
3 \\
4 \\
5 \\
6 \\
7 \\
8 \\
9\end{array}$ & $\begin{array}{c}-\overline{46} \\
24 \\
25 \\
\text { Heater } 1 \\
\text { Heater } 2 \\
13 \\
14 \\
15 \\
16\end{array}$ & $\begin{array}{l}\overline{5} \\
5 \\
5 \\
5 \\
5 \\
5 \\
5 \\
5 \\
5\end{array}$ & $\begin{array}{l}-1, \mathrm{~A} \\
2, \mathrm{~B} \\
3, \mathrm{C} \\
4, \mathrm{D} \\
5, \mathrm{E} \\
6, \mathrm{~F} \\
7, \mathrm{H} \\
8, \mathrm{~J} \\
9, \mathrm{~K}\end{array}$ & $\begin{array}{l}\text { R } \\
\text { E } \\
\text { L } \\
\text { A } \\
\text { Y }\end{array}$ \\
\hline $\begin{array}{l}\mathrm{L} \\
\mathrm{E}\end{array}$ & $\begin{array}{l}50 \\
51 \\
52\end{array}$ & Pipe loop & $\begin{array}{l}\text { V3 control } \\
\text { Pipe } \\
\text { Pipe }\end{array}$ & $\begin{array}{r}112 \\
44 \\
62\end{array}$ & $\begin{array}{l}3 \\
3 \\
3\end{array}$ & $\begin{array}{l}10 \\
11 \\
12\end{array}$ & $\begin{array}{r}21 \\
9 \\
6\end{array}$ & $\begin{array}{l}5 \\
5 \\
5\end{array}$ & $\begin{array}{l}10, \mathrm{~L} \\
11, \mathrm{M} \\
12, \mathrm{~N}\end{array}$ & $\mathrm{E}$ \\
\hline 8 & $\begin{array}{l}53 \\
-- \\
54 \\
55 \\
56 \\
57 \\
58 \\
59\end{array}$ & (Not in Use) & $\begin{array}{l}\text { Pipe } \\
\text { Pipe } \\
\text { Pipe } \\
\text { Pipe } \\
\text { Pipe } \\
\text { Pipe } \\
\text { Pipe }\end{array}$ & $\begin{array}{l}48 \\
-- \\
68 \\
66 \\
64 \\
60 \\
58\end{array}$ & $\begin{array}{l}3 \\
- \\
3 \\
3 \\
3 \\
3 \\
3\end{array}$ & $\begin{array}{l}13 \\
-- \\
14 \\
15 \\
16 \\
17 \\
18\end{array}$ & $\begin{array}{l}8 \\
7 \\
5 \\
4 \\
3 \\
2 \\
1\end{array}$ & $\begin{array}{l}6 \\
6 \\
6 \\
6 \\
6 \\
6 \\
6 \\
6\end{array}$ & $\begin{array}{l}1, \mathrm{~A} \\
2, \mathrm{~B} \\
3, \mathrm{C} \\
4, \mathrm{D} \\
5, \mathrm{E} \\
6, \mathrm{~F} \\
7, \mathrm{H} \\
8, \mathrm{~J}\end{array}$ & $\begin{array}{l}\text { E } \\
L \\
A \\
Y\end{array}$ \\
\hline
\end{tabular}


TABLE VI cont.

CHN: SYSTEM DESCRIPTION

$\begin{array}{lll}60 & -- & -- \\ 61 & \text { Glove box } & \text { GBI } \\ 62 & & \text { GB2 } \\ 63 & \text { Experimenters } & \text { Exl } \\ 64 & & \text { Ex2 }\end{array}$

L

E 65

G 66

67

68

69

970

71

72

73

74
$E \times 3$

$\mathrm{E} \times 4$

$\mathrm{E} \times 5$

$\mathrm{E} \times 6$

$\mathrm{E} \times 7$

$\mathrm{E} \times 8$

$E \times 9$

$\mathrm{E} \times 10$

ExII

$\mathrm{E} \times 12$
HP 3495A

T/C CARD CON HEATER

Ref.

200

201

202

203

$\begin{array}{ll}4 & 0 \\ 4 & 1 \\ 4 & 2 \\ 4 & 3 \\ 4 & 4\end{array}$

--
71
72
73
74

204

205

206

207

208

209

210

211

212

213

$\begin{array}{rr}4 & 5 \\ 4 & 6 \\ 4 & 7 \\ 4 & 8 \\ 4 & 9 \\ 4 & 10 \\ 4 & 11 \\ 4 & 12 \\ 4 & 13 \\ 4 & 14\end{array}$

\section{5}

76

77

78

$-$

$-$

$-$

$-$

$-$

HP6940B

CARD PINS

$\begin{array}{rrr}- & --- & S \\ 6 & 9, \mathrm{~K} & \mathrm{E} \\ 6 & 10, \mathrm{~L} & \mathrm{~T} \\ 6 & 11, \mathrm{M} & \\ 6 & 12, \mathrm{~N} & \mathrm{~F}\end{array}$

\section{Equipment Control}

Connections

Cold trap blower

Drain valve

vacuum pump

Sodium electromagnetic pump

Fail safe timer

$\begin{array}{rrrrrrr}-- & - & - & -- & 7 & 5, \mathrm{E} & \\ -- & - & -- & -- & 7 & 6, \mathrm{~F} \\ -- & - & -- & -- & 7 & 7, \mathrm{H} & \\ -- & - & -- & -- & 7 & 8, \mathrm{~J} & \mathrm{G} \\ -- & - & -- & -- & 7 & 10, \mathrm{~L} & \\ & & & & & \& 11, \mathrm{M} & \end{array}$


Date: $03 / 17$ Time $12: 54: 53$

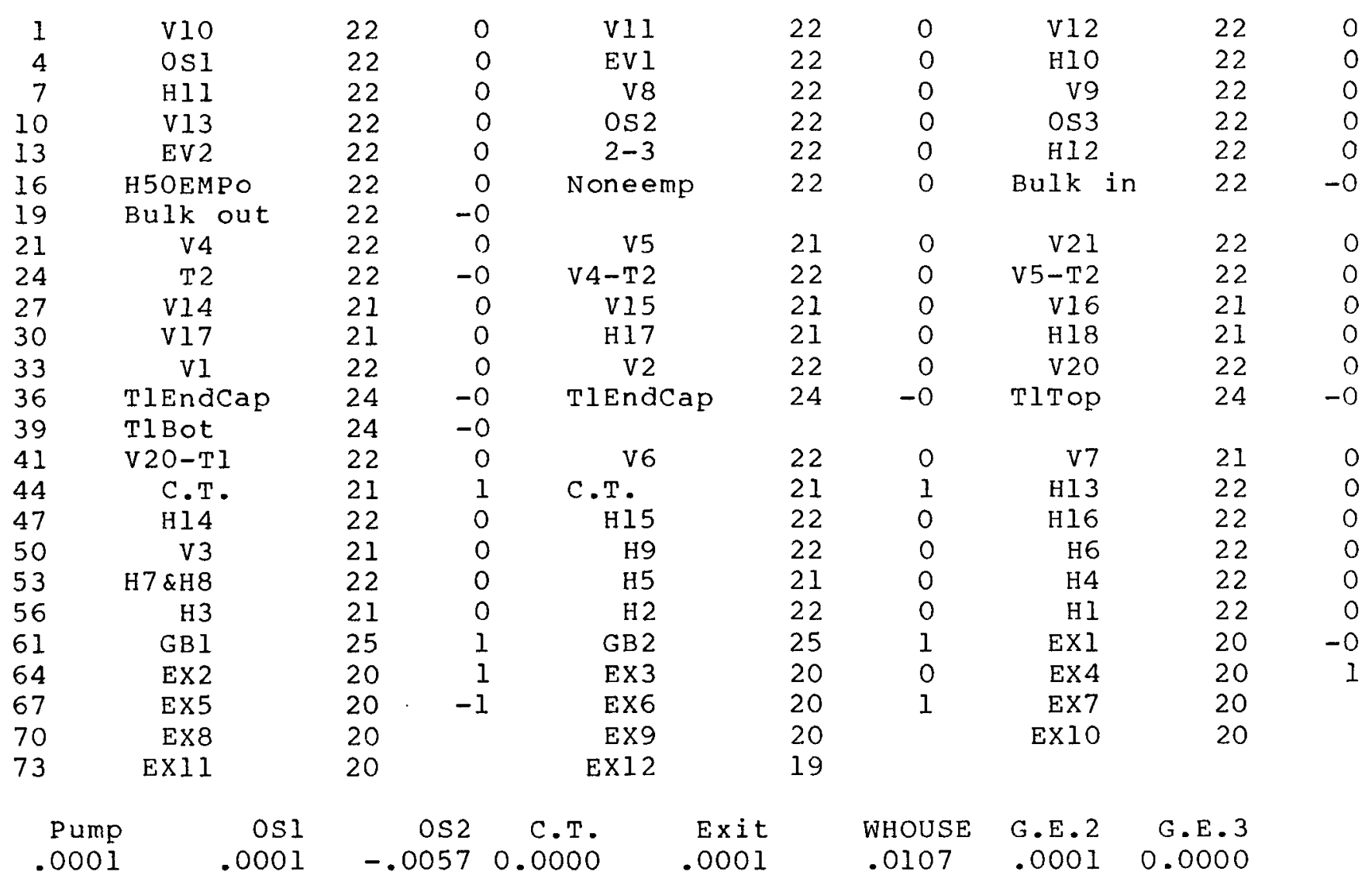

Fig. 21 screen display for one scan of control program 

1621 PUMP $\quad .000$
$\begin{array}{llll}18 & 22 & 0 S 1 & .000\end{array}$
$\begin{array}{llll}44 & 16 & 052 & .011\end{array}$
$45 \quad 16 \quad$ C.T. $\quad .000$
$\begin{array}{llll}70 & 18 & \text { EXIT } & 0.000\end{array}$

Figure 22. Screen Display in Large Type Mode (Control Program Keystroke "Big On") 
Manual Control

In addition to the computer control system, a very simple manual control system is available. Its function was to assist in the original check out of the $100 p$ and the computer control program. It also would be used to control the oxygen meter legs in the event of other control failures. Finally, the system is used as a monitor to check suspect thermocouples. Many locations around the loop have two thermocouples at the same place. If the computer is reporting an illogical temperature, the temperature of the companion thermocouple may be checked with the manual system in order to isolate whatever problem exists. The following items are included:

1. Temperature controller (4)

2. Switch, thermocouple 20 position (2)

The manual control system details are shown on drawings T74697, $\mathrm{CK}-\mathrm{T} 74697$, T74704 and $\mathrm{CK}-\mathrm{T} 74704$.

\section{OPERATING PROCEDURES}

The Safe Operating procedure for the sodium 1oop, SOP\#05500 8103, should be read before any attempt is made to operate the loop.

In all of the following procedures, it is assumed tht the loop is leak tight and is free of oxygen, moisture and other foreign substances. Since the loop has been in operation for several years, it is also assumed that the loop contains sodium in Tank Tl, in the cold trap and in numerous other places where small amounts of sodium do not freely drain when the loop is shutdown.

\section{Filling and Circulating sodium in the Loop}

All sections of the loop that are to be filled nust be above the melting point of sodium, $97.83^{\circ} \mathrm{C}$. In practice, the temperature is set to $200^{\circ} \mathrm{C}$. To accomplish this, refer to Appendix A on procedures to load and execute the computer control program. Follow the checklist in Table VII.

Sodium now fills the circulating portion of the loop. Flow may be established by manually setting the pump control variac to some low value such as 15 to $20 \%$. If pumping starts, it will be indicated on the pump flowmeter output meter which is just above the variac hand wheel and also on the computer screen. Quite often, pumping does not start immediately. In that case, leave the variac setting at 15 to $20 \%$ until pumping does start. It is common for a solid plug of sodium to exist in the pump even though temperatures indicate that all of the sodium should be melted. The pump thermal insulation, by design, is not as complete as other parts of the loop. Once flow is established, then the flow rate may be adjusted and the flow through the various legs of the loop partitioned. The experimental package should be brought to the same temperature as the loop and then valves 14 \& 15 orl6 \& 17 should be opened to allow sodium to circulate through the 


\section{TABLE VII \\ Checklist}

Filling the Loop with sodium

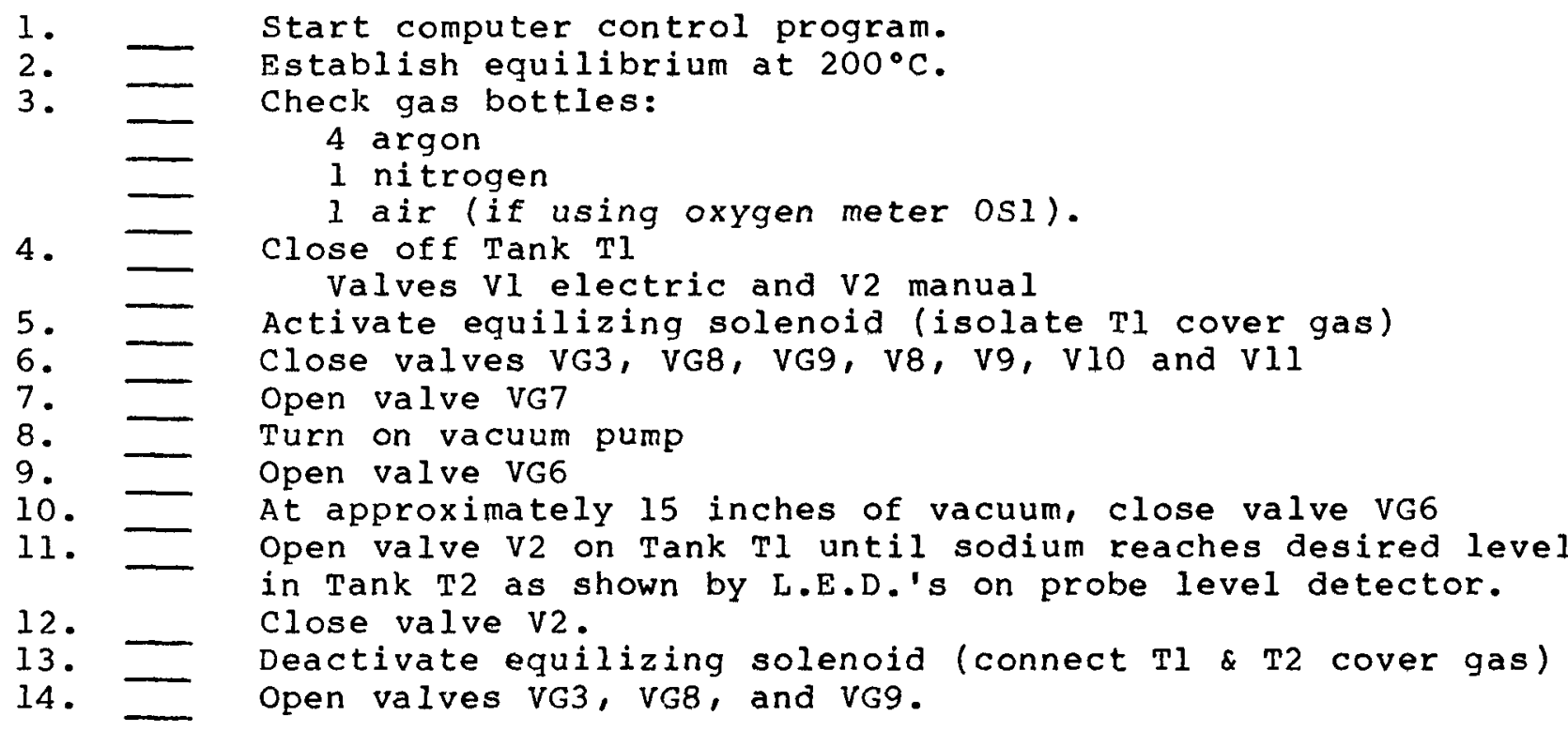

package. Now the temperature of the loop can be brought to operating conditions; $120^{\circ} \mathrm{C}$ on the cold trap and $400^{\circ} \mathrm{C}$ elsewhere. At these settings, the oxygen level in the sodium should drop to about $1 \mathrm{ppm}$ after about 4 days of circulating through the cold trap. An analysis report of the sodium furnished to two experiments is included as Appendix $B$.

\section{Shutdown}

Emergency shutdown may be accomplished by hitting any of the "panic" buttons. Normal shutdown can be achieved in several ways. The experimental package should be closed off from the rest of the loop by closing valves 14 and 15 or valves 16 and 17 , whichever is appropriate. Next, the oxygen meter leg valves should be closed (Valves $8,9,10$ and 11 ). The sodium can be drained into Tank 1 by opening Valve 1. The operator may drain the sodium at $400^{\circ} \mathrm{C}$ or may lower the temperature to $200^{\circ} \mathrm{C}$ before draining. It is best to have the temperature in Tank 1 the same as the sodium that will be draining into it to avoid thermal shock. The oxygen meter legs are not drained unless maintenance work is required on those legs. Their temperature is brought down slowly under either manual or computer control. Typically, about 12 psig of argon cover gas pressure is maintained on the loop at all times. 


\section{ACKNOWLEDGEMENT}

The authors wish to acknowledge the most welcome assistance of Malcolm Woodward in debugging the computer control program. 
1. Sodium-NaK Engineering Handbook, Vol 5, pg. 12, 0.J. Foust, Editor, Gordon \& Breach Science Publ., Inc., 1979.

2. A General Equation for the Solubility of oxygen in Liquid sodium, J.D. Noden, J. Brit. Nucl. Engr. Soc., Vol. 12, pg. 57-62, 1973.

3. Oxygen Potentials in Alkali Metals and Oxygen Distribution Coefficients Between Alkali and Structural Metals - an Assessment, O.M. Srudharam and J.B. Gnanamoorthy, J. Nucl. Mat., 89 (1980), pg. 113-128.

4. An Equilibrium and Kinetic study of the Liquid Sodium-Hydrogen Reaction and its Relevance to Sodium-water Leak Detection in LMFBR Systems, A.C. Whittingham, J. Nucl. Mat., 60 (1976), pg . 119-131.

5. Sodium Technology, North American Rockwell, 1970. 


\section{BIBL IOGRAPHY}

1. "Safe Operating Procedure for Sodium Purification Loop". Sandia National Laboratories SOP\# $0550081033 / 1981$.

2. "Security Plan for Uncleared Foreign Scientists Access to Sandia National Laboratories Tech Area V." Revised 6/17/82, pgs. 14-16.

3. "Security procedures for the Use, Testing, Processing or storage of Unclassified Category-I and Category-II Quantities of Special Nuclear Material in Tech Area III, Building 6505", Revised $1 / 5 / 82$.

4. "Safety Assessment Document-Sodium Purification Loop". 
APPENDIX A

Load and Execute Computer Control Program

I. Preliminary preparation

A. Verify that the following power panel breakers are on:

1. Power panel "A" - breaker 17

2. Power panel " $4 \mathrm{~L}$ " - breakers 10, 29, 35 and 41

B. Verify that the 5 volt power supply is on.

C. Verify that the ELGAR LINE CONDITIONER is on.

D. Verify that the two HP $3495 \mathrm{~A}$ scanners are on.

E. Verify that the HP 6940B MULTIPROGRAMMER is on.

F. Verify that the HP 59500A MULTIPROGRAMMER INTERFACE is on.

G. Verify that the HP 3455A DIGITAL VOLTMETER is on.

H. Verify that the two Keithley 642 ELECTROMETERS are on.

I. Verify that the "fail safe timer" is on.

II. Operating Procedures

A. Load tape cassette titled "AUTOST" into the right cassette drive of the $9845 \mathrm{~B}$.

1. If the HP $9845 \mathrm{~B}$ is turned of $\mathrm{f}$ :

a. Verify that AUTOST button is depressed.

b. Turn on the HP $9845 \mathrm{~B}$ (the power switch is on the right side of the computer). The program will be loaded into the computer and will start to execute automatically.

c. Proceed to Paragraph III.

2. If the HP $9845 B$ is turned on:

a. Depress the key switch marked "K9" or "LOAD". The word LOAD will appear on the screen.

b. Type in: "AUTOST". The following is now displayed on the screen. Load "AUTOST".

c. Depress the "EXECUTE" key. The program "AUTOST" is then read into the computer. A square will appear on the lower righthand edge of the screen. This square indicates that the computer is busy. When the square disappears, the computer is ready for the next instruction. 
d. Depress the "RUN" key. This starts program execution.

III. Program Execution

A. Program Identification (TITLE) - The program first outputs the program identification on the CRT as follows:

BIdg. 6505 - SODIUM PURIFICATION LOOP CONTROL PROGRAM

B. Date and Time (DATE) - The subprogram outputs the current date and time as follows:

Date: MM/DD Time: Hr:Mn:Ss

C. Temperature Read (RDTEMP) - The subprogram then reads in and displays all of the system temperatures. Temperatures are in degrees centigrade.

D. Initial System Conditions (INITAL) - The subprogram examines the system temperatures and determines the initial conditions of the system. The following conditions are determined:

1. If all temperatures are within $2^{\circ} \mathrm{C}$ of the ambient temperature, the program outputs:

$$
\begin{aligned}
& \text { System at Ambient } \\
& \text { No FLOW, NO HEATERS }
\end{aligned}
$$

2. If some of the temperatures are at ambient and others are elevated, the program outputs:

$$
\begin{gathered}
\text { Part of system Elevated } \\
\text { NO FLOW, }
\end{gathered}
$$

3. If all temperatures are elevated but some are below $120^{\circ} \mathrm{C}$, the program outputs:

$$
\begin{aligned}
& \text { System Temperatures Too Low for Flow } \\
& \text { NO FLOW, MAINTAINING TEMPERATURES }
\end{aligned}
$$

4. If all temperatures are above $120^{\circ} \mathrm{C}$, then the program outputs:

$$
\begin{array}{cl}
\text { System Ready for Flow } \\
\text { FLOW POSSIBLE, } & \text { MAINTAINING TEMPERATURES }
\end{array}
$$

E. System Control Loop - The program reads the temperatures one more time before going into a control loop that consists of:

1. Reading temperatures (RDTEMP).

2. Determining which heaters are to be turned on (TPMON). 
3. Applying heaters if required (HEATER).

4. Checking for any system changes (STROKE).

5. Return to 1 .

F. System Changes (STROKE) - System changes are entered from the keyboard. The operator types in a command followed by a "STORE," "CONT," or "EXCUTE" key. Other changes can be executed by depressing one of the control keys, on the upper righthand side of the keyboard of the $9845 \mathrm{~B}$ computer, KO through KI5 (these will be discussed in detail later). some commands just require a single keystroke, while others are follows by additional instructions. The "BACK SPACE" and "BACK ARROW" keys delete a character from the input string. The "CLEAR LINE" key clears the input string. The commands are as follows:

1. Command String: TITLE - This command outputs the same information as presented in Paragraph III.A.:

Bldg. 6505 - SODIUM PURIFICATION LOOP CONTROL PROGRAM

2. Command string: CLOCK - The command interrogates the HP 98035A Real Time Clock for the current date and time.

a. The program outputs:

Month: MM Day: DD

* IS DATE CORRECT* Y(ES) or N(O)?

If the date is correct, the operator depresses the "Y" key and then the "CONT" key. The program advances to step $c$.

b. If the date is incorrect, the operator depresses the "N" key and then the "CONT" key. The program continues:

*ENTER NUMERIC Month* 01 (JAN)-12(DEC)?

The operator then types in the month followed and presses the "CONT" key. The program then outputs:

*ENTER Day*?

After the operator enters the day, the program returns to step a.

c. The program then outputs:

Time: $\mathrm{Hr}: \mathrm{Mn}: \mathrm{Ss}$

* IS TIME CORRECT* Y(ES) or N(O)? 
d. If the time is correct, the operator depresses the "Y" key and then the "CONT" key. The program goes to step $\mathrm{f}$.

e. If the time is correct, the operator depresses the "N" key and then the "CONT" key. The program continues:

*ENTER Time* FORMAT: Hr:Mn:Ss?

After typing in the time and pressing the "CONT" key, the program proceeds to step $c$.

f. If the date or time was corrected, then the program resets the HP $98035 \mathrm{~A}$ Real Time Clock. In either case, the program outputs:

Date: MM/DD Time: Hr:Mn:Ss

3. Command string: DATE - This command outputs the current data and time as follows:

Date: MM/DD Time: Hr:Mn:Ss

4. Command string: TIME - This command outputs the current time as follows:

Time: Hr:Mn:Ss

5. Command string: INITAL - This command examines the system temperatures and determines the initial conditions of the system. Refer to Paragraph III.D. for the initial conditions.

6. Command String: EQUIP - This command lists the equipment on the HPIB bus.

7. Command string: CHGTMP - This command allows for the changing of the system control temperatures. The temperatures for the entire system, a given leg, or a specified channel can be changed.

a. After entering the command string, the program follows up with the query:

ENTER SYS or LEG or CHN:

b. If the operator enters SYS, the program follows up with the query:

ENTER Desired New Temperature:

After entering the temperature and when the subroutine CHGTMP is called, valves will be set 18 
higher than the pipe temperatures and exit pipes will be .58 higher.

NOTE: When changing system temperatures upward, the cold trap temperatures are restricted to $122^{\circ} \mathrm{C}$ $(T P C O L D)$ if fan $=1$.

When changing system temperatures downward, the oxygen meter temperatures will be held at their highest temperature. If it is desired to lower the oxygen meter temperature, the LEG command must be used for each leg.

c. If the operator enters LEG, the program follows up with the second query:

ENTER Leg Number: Values 0 thru 9:

Each leg represents part of the system as defined below:

Leg Number

Leg Definition

0

1

Oxygen Meter Loop 1

Oxygen Meter Loop 2

Electromagnetic Pump

Bulk Heater

T2, Expansion Volume

Exit Pipes

Tl, Storage Tank

Cold Trap

Pipe Loop

Glove Box and Experimenters

After entering the leg number, the program follows with the query:

ENTER Desired New Temperature:

After entering the temperature and when the subroutine CHGTMP is called, valves will be set $1 \%$ higher than the pipe temperatures and exit pipes will be .5\% higher.

d. If the operator enters $\mathrm{CHN}$, the program follows up with the second query:

ENTER Channel Number:

After entering the channel number, the program follows with the query:

ENTER Desired New Temperature: 
After entering the temperature and when the subroutine CHGTMP is called, the new temperature value is set.

8. Command string: PRINTER - This command allows the operator to change all printing from the screen (16) to paper hard copy (0), and back again. After entering the command string, the program follows up with the query:

ENTER 0 or $16:$

The operator can then decide where he wants his printing: Screen (16) or Paper (0).

9. Command string: TMEMIN - This command string allows for the setting of the minimum heater time. After entry, the program follows up with the query:

ENTER New Value:

The time value is in seconds.

10. Command String: TMEMED - This command string allows for the setting of the median heater time. This command string operates in a similar manner as TMEMIN, as in 9 above.

11. Command string: TMEMAX - This command string allows for the setting of the maximum heater time. This command string operates in a similar manner as TMEMIN, as in 9 above.

12. Command string: TPCOLD - This command string allows for the setting of the Cold Trap temperature. After entry, the program follows up with the query:

ENTER New Value:

The temperature value is in degrees centigrade.

13. Command string: TMPLIM - This command string allows for the printing of the Temperature Limits table.

14. Command String: DEG.C - This command string allows for program control and printing of temperatures in degrees centigrade.

15. Command String: DEG.F - This command string allows for program control and printing of temperature in degrees Fahrenheit.

16. Command string: FAN - This command string allows for the operation of the cold Trap fan. After entry, the 
ENTER New Value:

Value

Fan Operation

0

off

1

On

NOTE: When fan $=I$, the temperature setpoint of Channels 44,45 and 46 are set at $122^{\circ} \mathrm{C}$ and are not affected by the CHGTMP commands until fan is turned off. When the fan control is turned off, the setpoint of Channels 44,45 and 46 will be controlled by the setpoint of Channel 41 .

17. Command String: DRAIN - This command string allows for the operation of the Sodium Drain valve. After entry, the program follows up with the query.

ENTER New Value:

Value

0

1

Valve Position

Open

close

18. Command string: VACUUM - This command string allows for the operation of the System vacuum Pump. After entry, the program follows up with the query:

ENTER New Value:

Value

0

1
Vacuum Pump Operation

off

on

19. Command String: PUMP - This command string allows for the operation of the Electromagnetic Pump. After entry, the program follows up with the query:

ENTER New Value:

Value

0

1
Pump operation

Off

Enable

NOTE: The Pump is enabled and not on. The Pump is turned on and its speed is controlled through a variac which is located below the 5 -volt power supply. 
G. The following commands are executed by depressing the command key and then answering any questions asked by the computer. The user must then press the "CONT" key to execute command.

1. Command Key: PAUSE - This key allows the computer operation to be temporarily suspended. After entry, the program follows up with the query:

System Paused: Press CONT to Continue:

When the operator is done, he can press the "CONT" key to continue the program.

2. Command Key: KO (CRT) - This key produces the Command: PRINTER $=16$.

3. Command Key: Shift KO (PRINTER) - This key produces the command: PRINTER $=0$.

4. Command Key: KI (CHG. TEMP SYST)

5. Command Key: K2 (CHG. TEMP LEG O) - This key produces the command: Enter Desired New Temperature

6. Command Key: K3 (CHG. TEMP LEG 1) - This key produces the command: Enter Desired New Temperature.

7. Command Key: K4 (FAN ON) - This key produces the command: $\mathrm{FAN}=0$ (sets temp. of $\mathrm{CHN}$ 's 44,45 , and 46 to the setpoint of $\mathrm{CHN} 24$ ).

8. Command Key: Shift K4 (FAN ON) - This key produces the command: $\mathrm{FAN}=1$ (Sets temp. of CHN's 44, 45, and 46 to $122^{\circ} \mathrm{C}$ ).

9. Command Key: K5 (DRAIN CLOSE) - This key produces the command: DRAIN $=0$.

10. Command Key: Shift K5 - This key produces the command: DRAIN $=1$.

11. Command Key: K6 - This key produces the command: VACUUM $=0$.

12. Command Key: Shift K6 - This key produces the command: $\mathrm{VACUUM}=1$.

13. Command Key: K7 - This key produces the command: PUMP $=0$.

14. Command Key: Shift K7 - This key produces the command: PUMP $=1$. 
15. Command Key: K8 - This key produces the command: DEG.C.

16. Command Key: Shift K8 - This key produces the command: DEG.F.

17. Command Key: K9 and Shift K9 (NOT IN USE).

18. Command Key: Klo - This key produces the command: RELAY OPTION. This option gives a computer readout of the relays status and also a read-back from the relays for comparison.

19. Command Key: Shift KIO (NOT IN USE).

20. Command Key: KIl - This key produces the command: PUMP MONITOR. This command monitors the flow meter for the sodium pump. If the output of the flow meter drops below. $5 \mathrm{~V}$, the program will shut the pump off (PUMP = o).

21. Command Key: Shift Kll - This key produces the command: NO PUMP MONITOR.

22. Command Key: KI2 - This key produces the command: RECORD DATA. The program will then interrogate the user to find out which recording device to use-cassette tape or floppy disc.

23. Command Key: Shift K12 - This key produces the command: STOP RECORDING DATA.

24. Command Key: Shift Kl3 (BIG ON) - The computer will now ask you for five CHN's to read. These five CHN's and the five flow readings will now be printed on the screen in large type. No other readings will be printed on the screen.

NOTE: For a readout of the other CHN's, depress command key "SHIFT KO" (Printer).

25. Command Key: Shift K13 (BIG OFF) - This key produces the command: BIG OFF. The key returns to the screen to its normal printout.

26. Command Key: Shift Kl4 (ALARM SET) - This key produces the command: SETMAX. The computer will now ask you to "ENTER ALARM TEMPERATURE (DEGREES FAHRENHEIT)." This temperature is different from the setpoint used to control the temperature of the sodium loop.

NOTE: If five temperature channels reach the alarm temperature setpoint, the computer will stop the 
execution of the program. The heaters, pump, and cold Trap fan will be turned off, and the loop will drain if the key switch is not in the manual mode.

27. Command Key: Shift K14 - This key produces the command: SET DISC TIME or SET TAPE TIME (the printout depends on which recording device you have selected. If you haven't chosen one yet, the computer will ask you which you want to use).

The computer will then output to the screen:

ENTER TIME BETWEEN DISC (OR TAPE)

RFCORDS (MINUTES)

(If you do not use key $\mathrm{Kl} 4$ to select a record interval, the computer will record each scan.)

28. Command Key: K15 (SCAN FAST) - This key produces the command: RAPID. In this mode of operation, the computer reads and prints only Channels $1-15$ (oxygen meter loops 1 and 2). Note: In this mode, the system heaters are not being turned on. This mode is used when first opening oxygen Legs 1 and 2 to allow sodium flow to be established. In this mode you can monitor any rapid changes in temperature which might be harmful to the oxygen meters.

29. Command Key: Shift Kl5 (SCAN REG.) - This key produces the command: NORMAL. This key returns the computer to its normal printout and resumes controlling the system heaters. 


\section{APPENDIX B}

Sodium Chemical Analysis 


\section{LOS AIDMOS}

Los Alamos National Laboratory

Los Alamos, New Mexico 87545

October 15, 1982

Dr. D. J. Sasmor

Organization 9453

Sandia National Laboratories

P. 0. Box 5800

Albuquerque, NM 87185

Dear Or. Sasmor:

The two metallic sodium samples submitted per Purchase Document Number 26-8585 (July 19, 1982) have been analyzed for oxygen and uranium. Duplicate weighed $\sim 5-g$ samples were distilled, the residues were dissolved in acid, and the resulting solutions were analyzed for sodium by atomic absorption and for uranium by isotope-dilution mass spectrometry. A blank was processed concurrently and the results were corrected for it. The sodium result was converted to an oxygen value by a factor of 0.348 . The analytical results for the sodium contents in the residues and the conversions to oxygen concentration in the sample are:

\begin{tabular}{|c|c|c|c|c|c|}
\hline Sample & $\begin{array}{l}\text { Sample } \\
\text { wt, g }\end{array}$ & $\begin{array}{l}\text { Total } \mathrm{Na} \text { in } \\
\text { Residue, } \mu \mathrm{g}\end{array}$ & $\begin{array}{l}\text { Total Na in } \\
\text { Residue Corr } \\
\text { for Blank, } \mu \mathrm{g}\end{array}$ & $\begin{array}{l}\text { Equivalent } \mathrm{O}_{2} \\
\text { in Residue, corr } \\
\text { for Blank, } \mu \mathrm{g}\end{array}$ & $\begin{array}{c}\mathrm{O}_{2} \text { in } \\
\text { Sample, } \\
\mu \mathrm{g} / \mathrm{g}\end{array}$ \\
\hline
\end{tabular}

D-7

Blank $\quad 3.3$

Portion 14.844

Portion $2 \quad 4.463 \quad 16.8$

14.4

5.0

1.0

13.5

4.7

$1.0_{5}$

$\underline{0-9}$

Blank - 6.2

Portion $15.523 \quad 7.7$

1.5

0.52

0.1

Portion 2

5.093

10.2

4.0

1.4

0.3 
Dr. S. J. Sasmor

The uranium contents of both samples were negligible, being less than 1 microgram of uranium per gram of sodium.

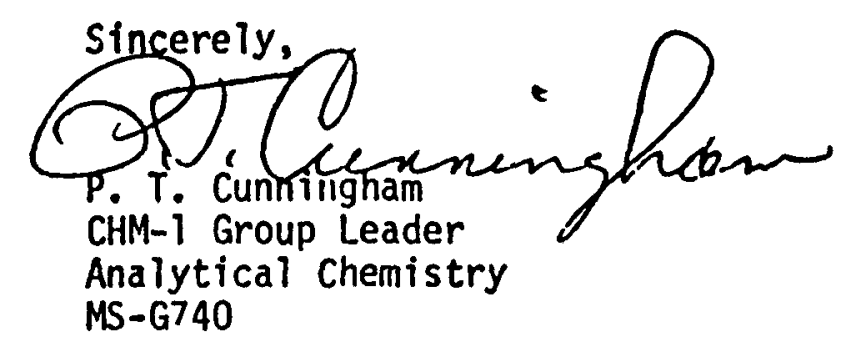

PTC:VMm

Cy: G. Rosenblatt, CHM-DO, MS-J563 CRMO (2), MS-A 150

CHM-l Analytical File 23879

CHM-1 Analytical File 24179

File (3) 
APPENDIX C

Data Graphs 


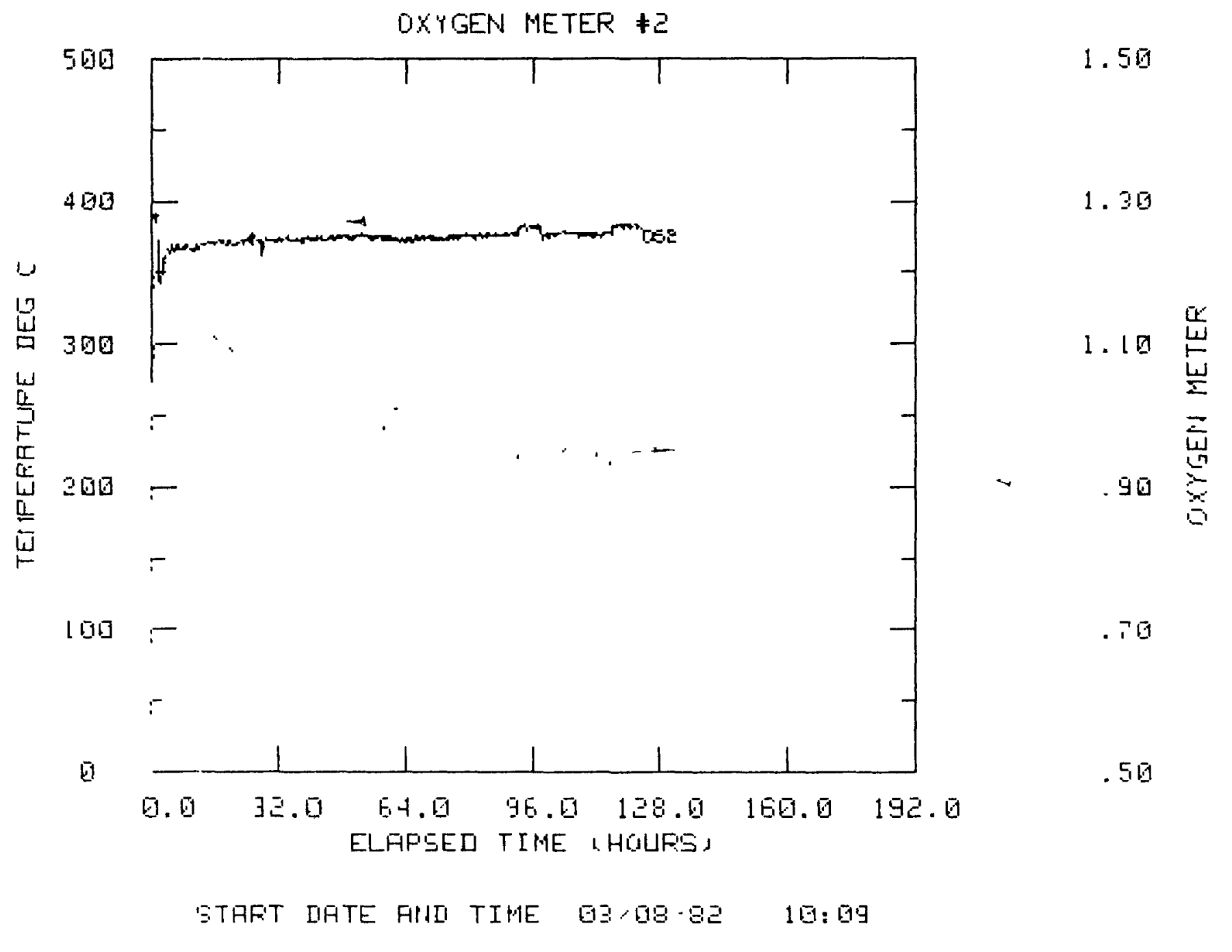




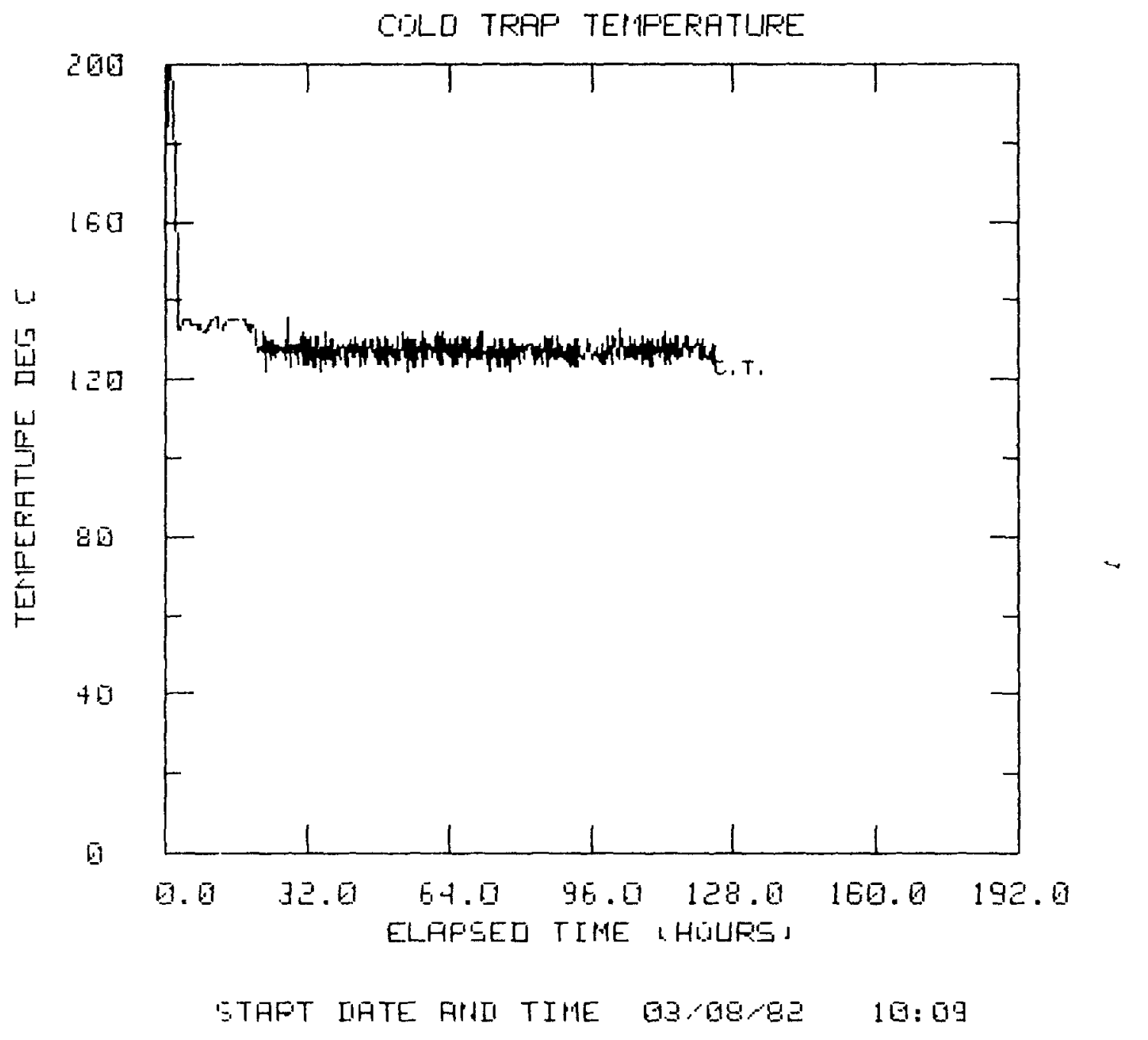




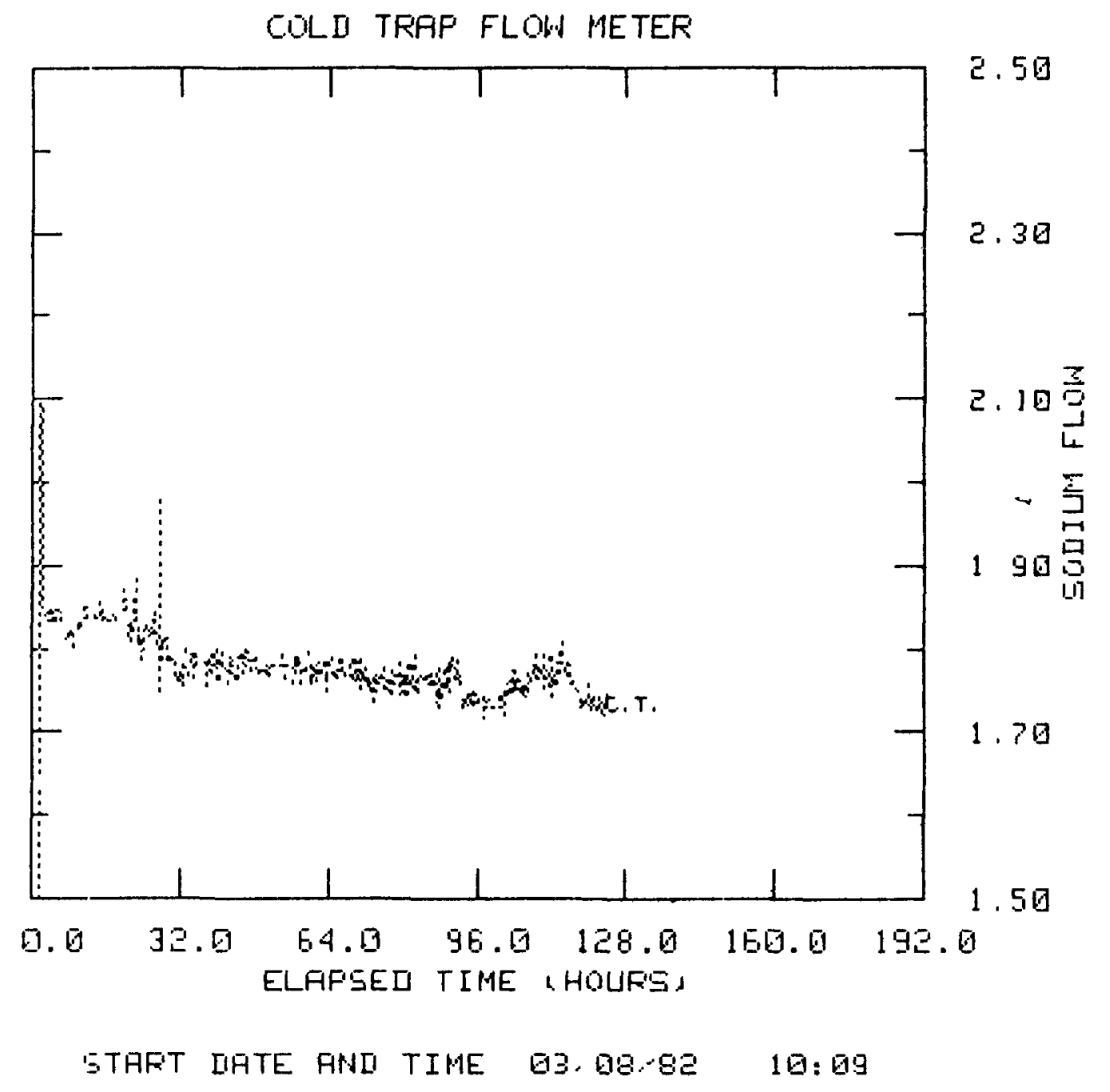




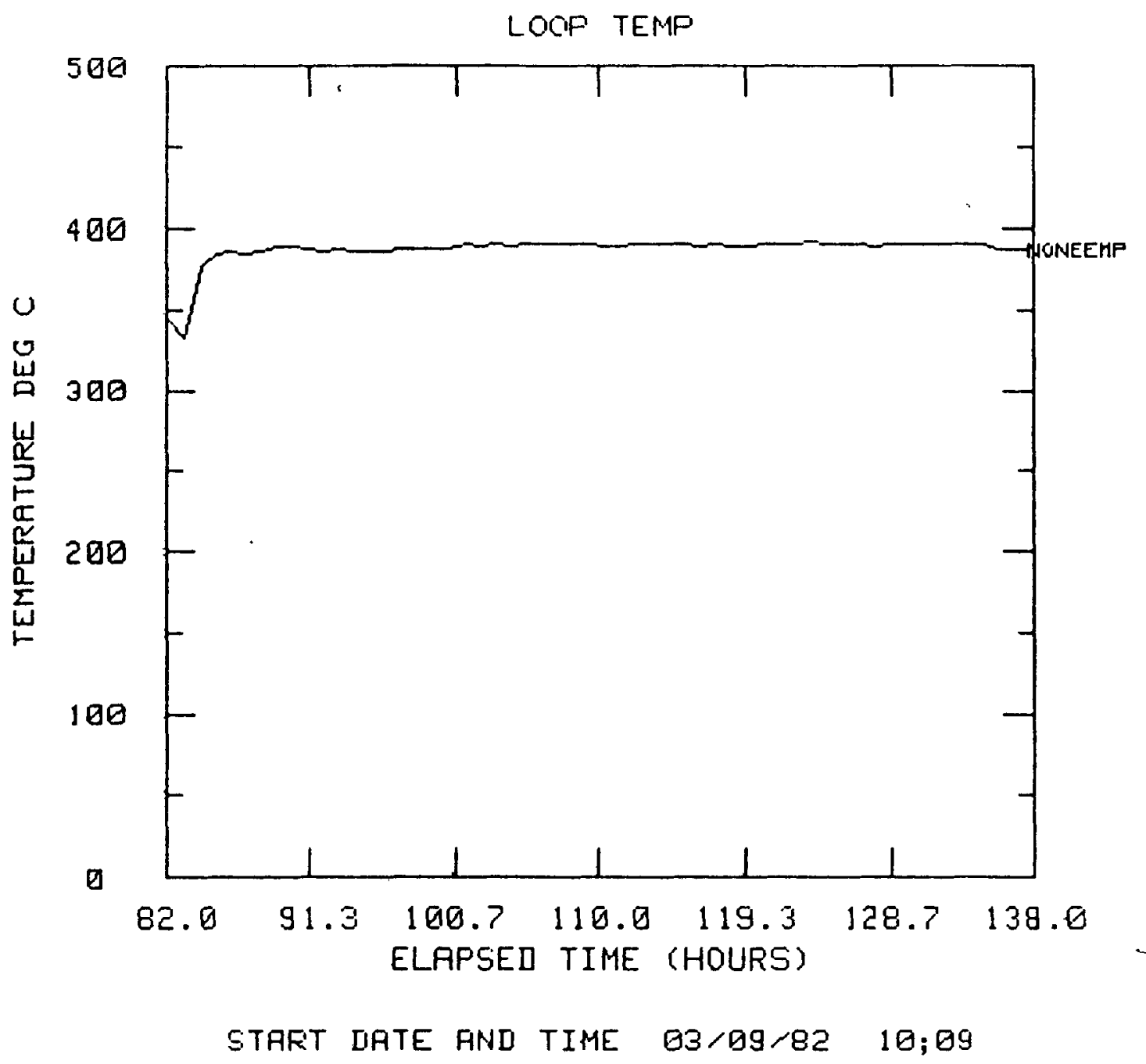


APPENDIX D

Sodium Loop Drawing List and

Referenced Drawings 
APPENDIX D

SODIUM LOOP DRAWING LIST

DRAWING NO.

DESCRIPTION

T61519

TS1520

T61521

TE1522

TE1523

T51524

TE1525

T61677

T61678

TE1679

T61680

T61681

T61682

T61683

TE1684

T61685

161709

T62639

T62645

TE3746

T63747

T63748

TE3814

T65484

T66642 (2)

T66957

T6E958

T66975

T66976

T66977

T69625

T69679

T70609

T72443

T72444

T72445

T73298

T73454

173934

$T 74697$ (2)

T74704 (3)

T74723

T74724

T74725

T74876

T74.877

T74878

T74938

FLOW METER ASSEMBLY

MAGNET YOKE

POLE SUPPORT, $3 / 4$ INCH

POLE SUPPORT, $1 / 2$ INCH

PIPE, $3 / 4$ INCH

PIPE, $1 / 2$ INCH

STUD, BRASS

ECONOMIZER, COLD TRAP

TANK, STORAGE T1

TANK, EXPANSION T2

TANK, HEATER

EXPANSION TANK, OXYGEN METER

STRUCTURE, SUPPORT

HOUSING, COLD TRAP

COLD TRAP

SIDE INLET, METER HOUSING

WELDMENT, SODIUM LOOP

UAPOR TRAP

MODIFIED HOUSING, OXYGEN METER

LEVEL INDICATOR ASSEMBLY

FEEDTHRU, 8 PIN, T1

FEEDTHRU, 7 PIN, T2

LEVEL INOICATOR, EXPANSION TANK, T2

FLANGE, BLANK OFF

NA PURIFICATION ROOM, BLDG.6505

ALUMINA

KOUAR TUBE

KOUAR TUBE, LARGE

ALUMINA, 7 PIN

ALUMINA, 8 PIN

INSULATOR, LOOP FURNACE

SCHEMATIC, SODIUM LOOP

WRENCH, SPANNER

ADAPTER, THERMOCOUPLE

BLOCK, THERMOCOUPLE

FIGURE 13

THERMOCOUPLE MOUNT ASSEMBLY

THERMOCOUPLE LOCATIONS, SODIUM LOOP\} FIGURE 14

COLD TRAP, HEATERS AND THERMOCOUPLES

HEATSINK, MOD. RELAY

TEMPERATURE MONITOR CHASSIS \#2

TEMPERATURE MONITOR CHASSIS \#1

HANGER LAYOUT

STRAP

SPACER

COUER GAS SYSTEM

TANK T1 HEATERS

TANK T2 HEATERS

PLUMBING, UACUUM PUMP 
174943

$T 75475$

T75476

T75507

$T 75604$

T76176

T76733

T76749

$T 77515$

T77526

T85727

69747

96071
CONNECTOR FLANGE

FLANGE, BLANK OFF

SOOIUM FILL. LINE

CROSSOUER SODIUM FLOW

PANEL, ARGON GAS IN

HEATER ASSEMBLY (HEATER LIST )

PANEL, HEAT SINK

SOLID STATE RELAY ENCLOSURE PANEL

RING, INSULATION SUPPORT, COLD TRAP

ELECTRICAL JUNCTION BOX LOCATION

HEATER LOCATIONS, SODIUM LOOP

WIRING OIAGRAM ALARM PANEL (PLANT ENGR.) SECURITY COMMAND CENTER ALARM PANEL 


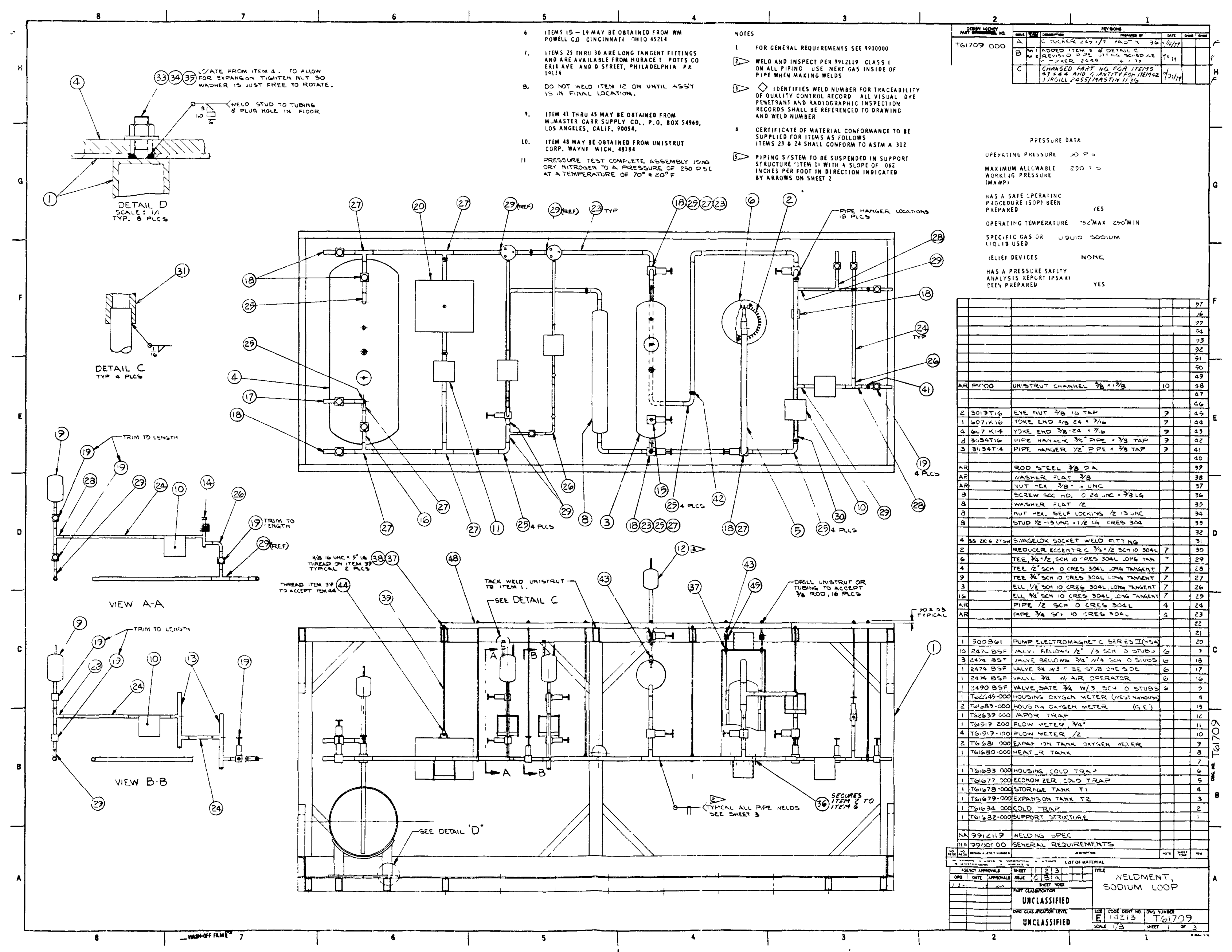




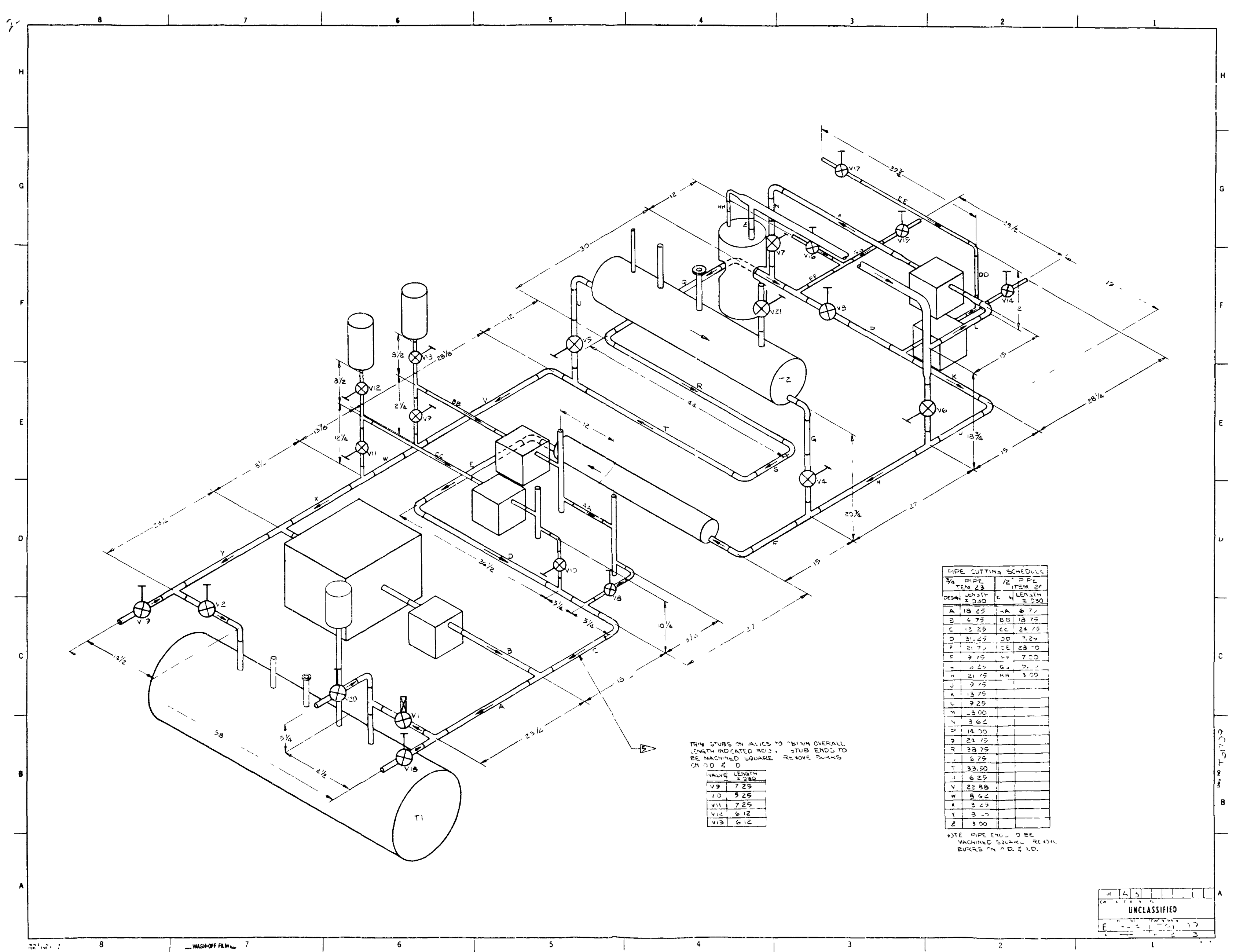





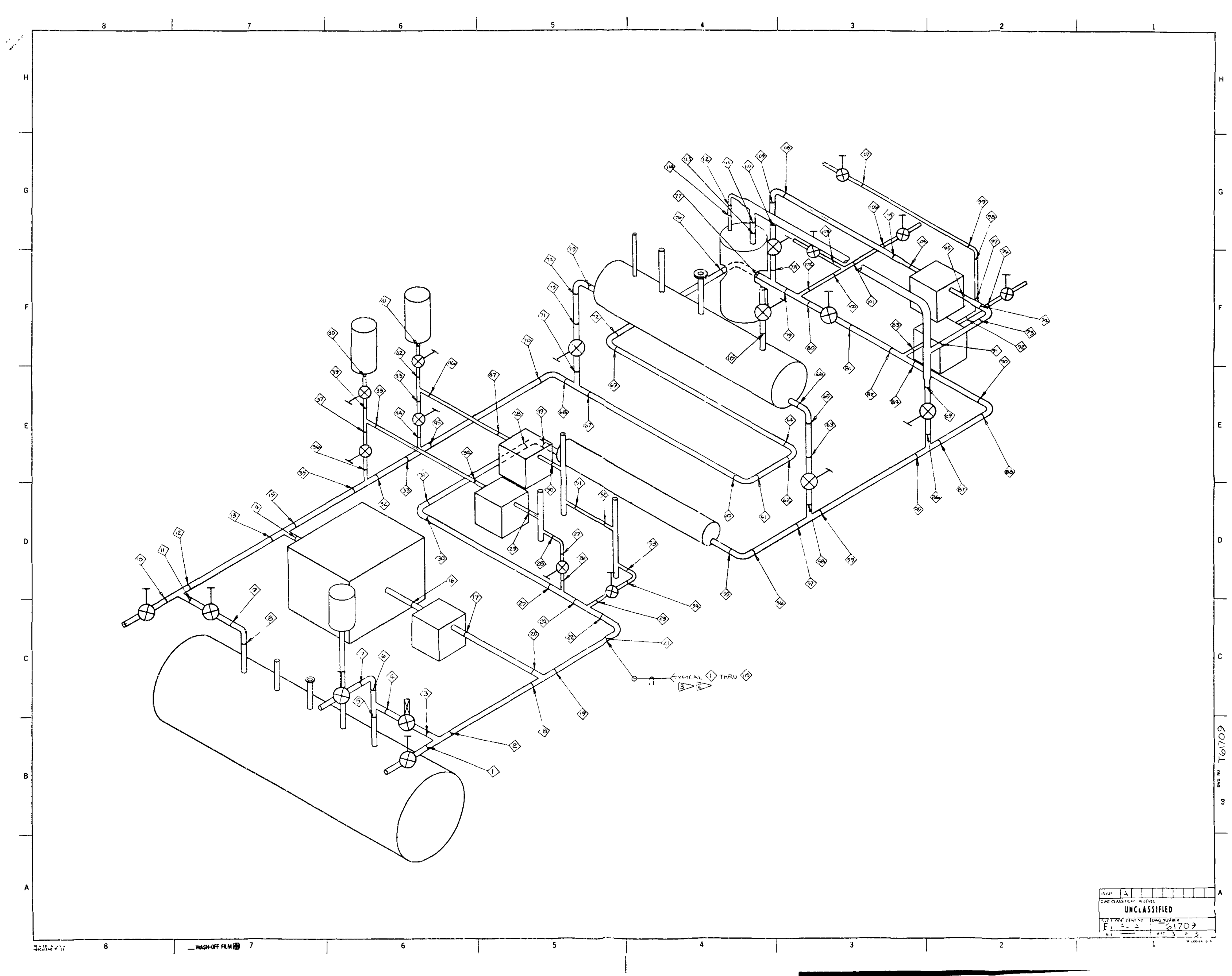





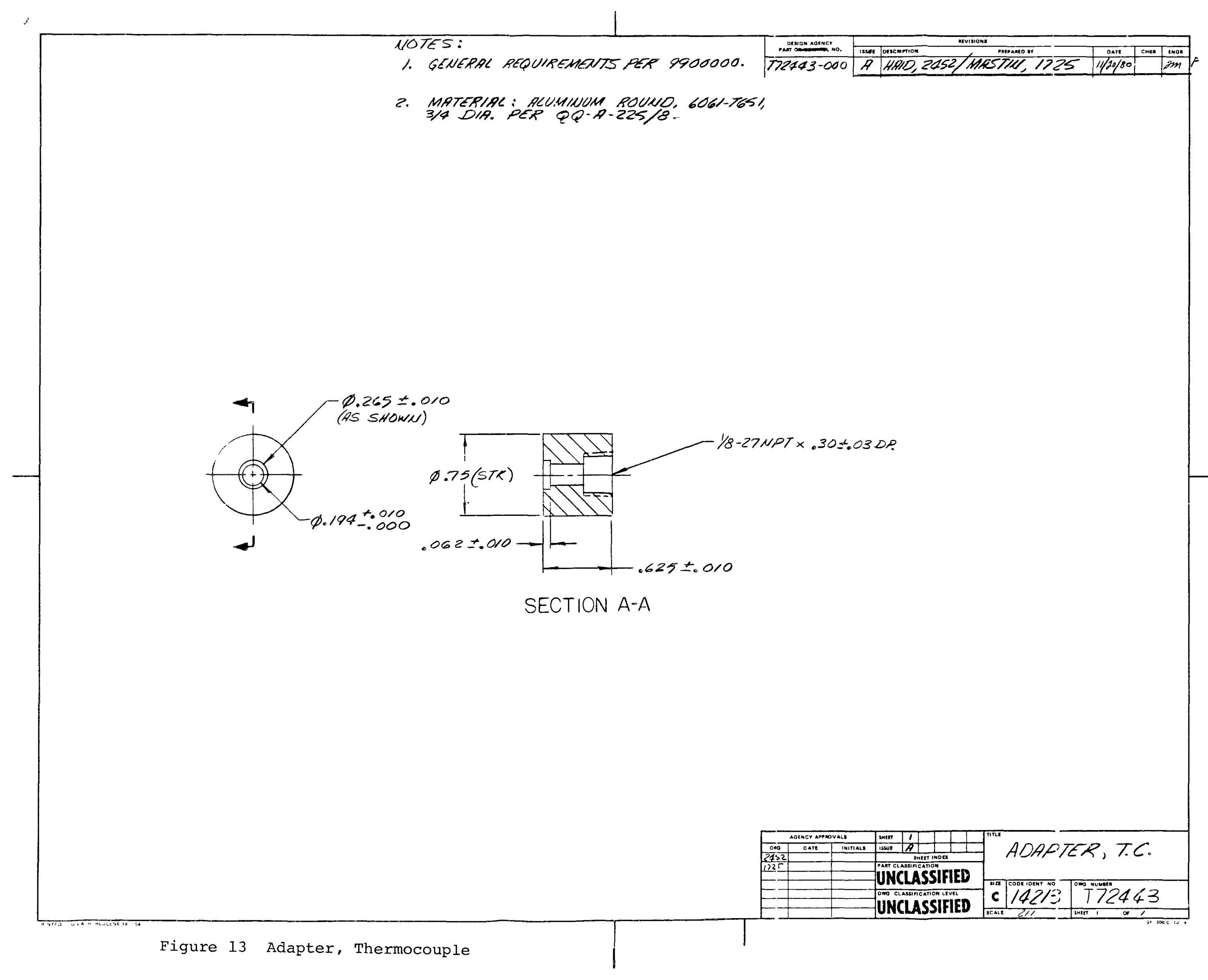





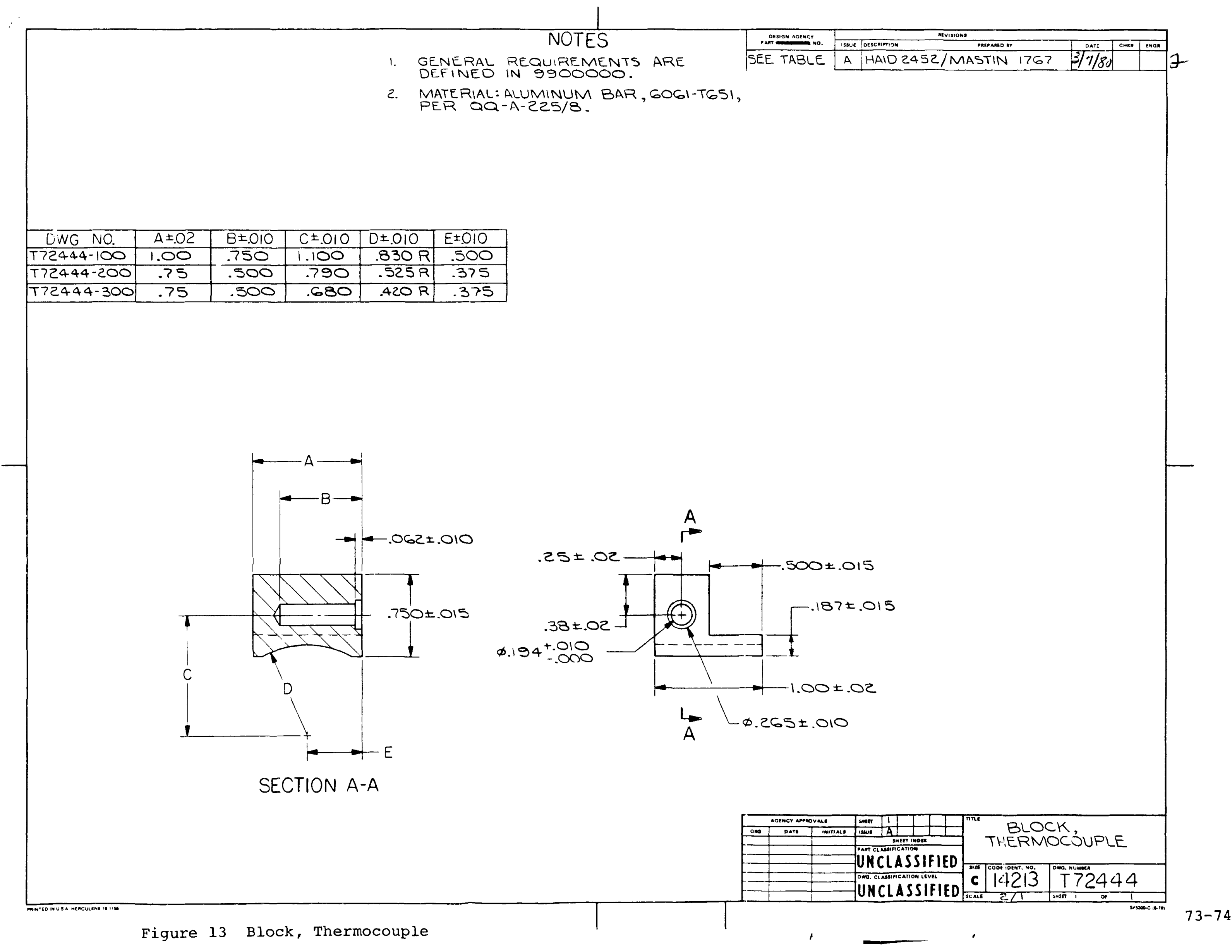




\section{NOTES}

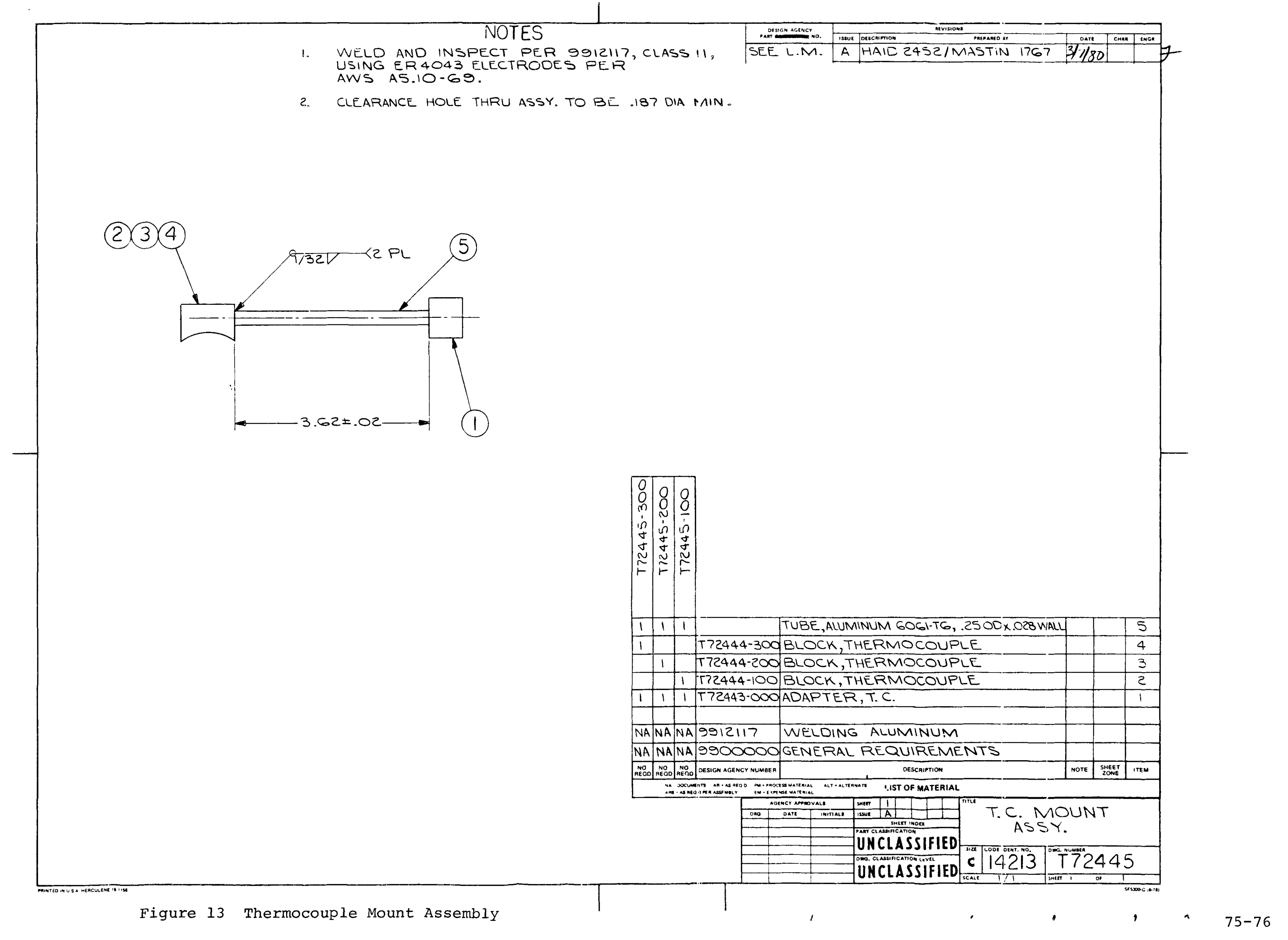




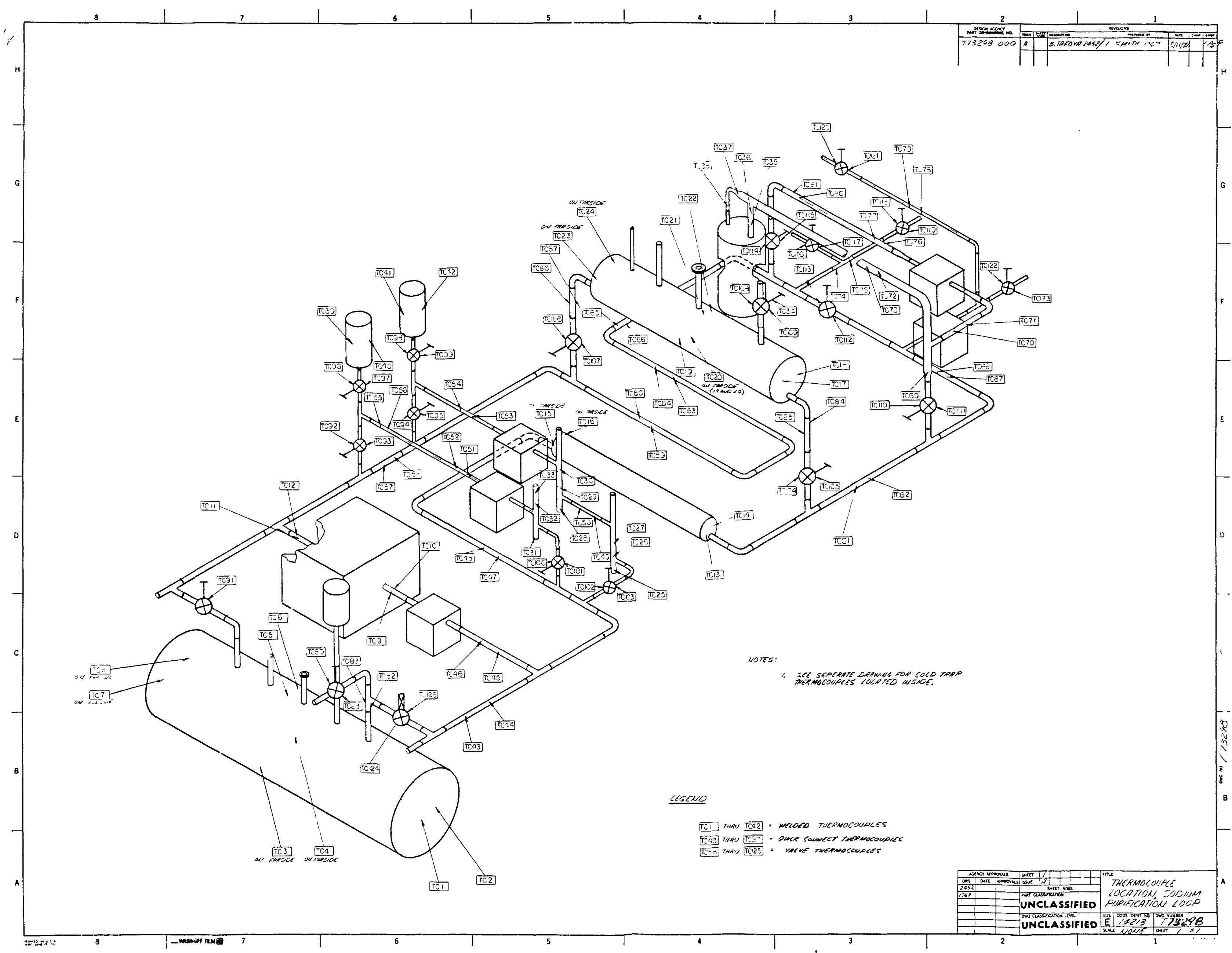

Figure 14 Thermocouple Locations, Sodium Loop 


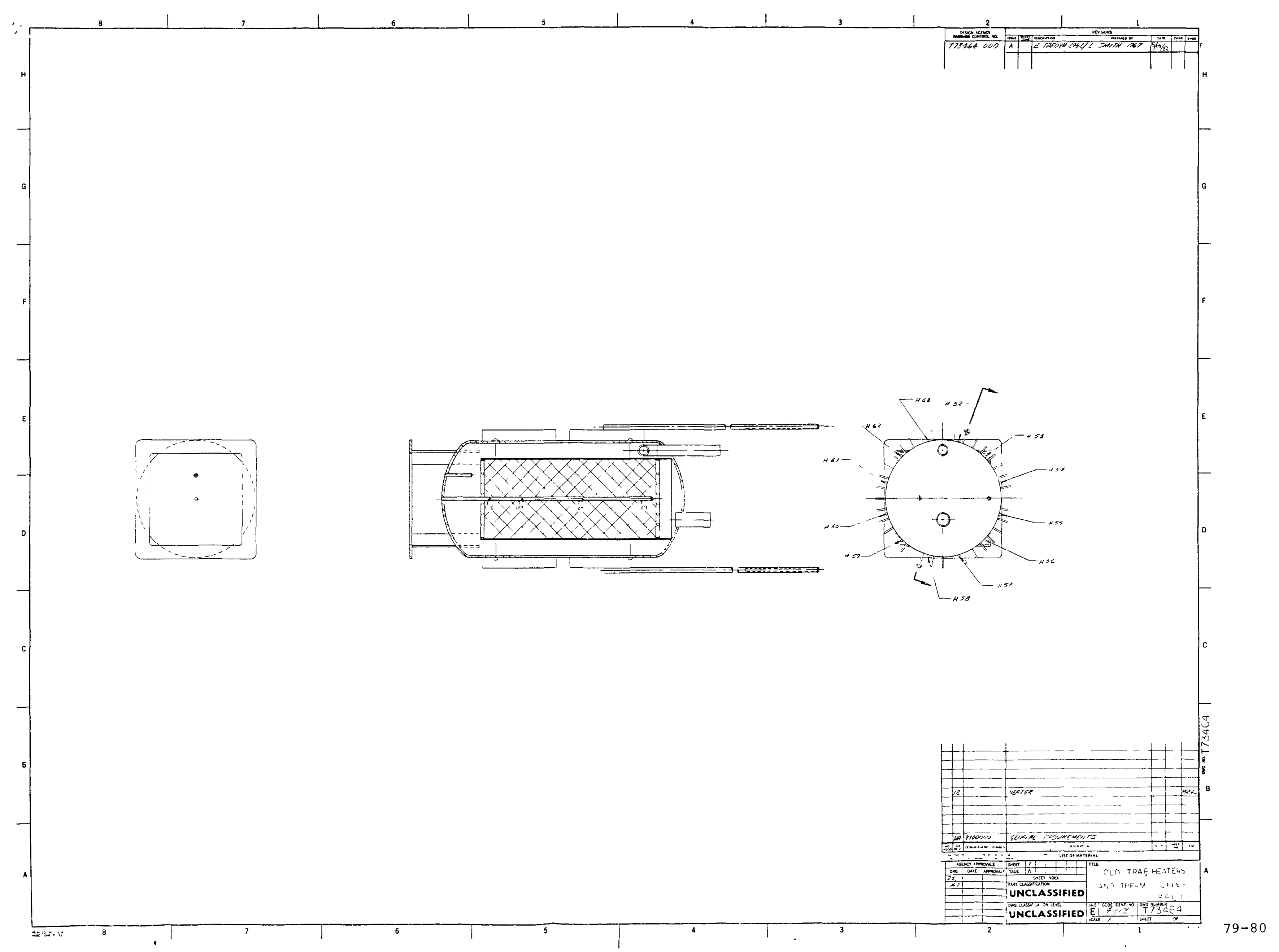





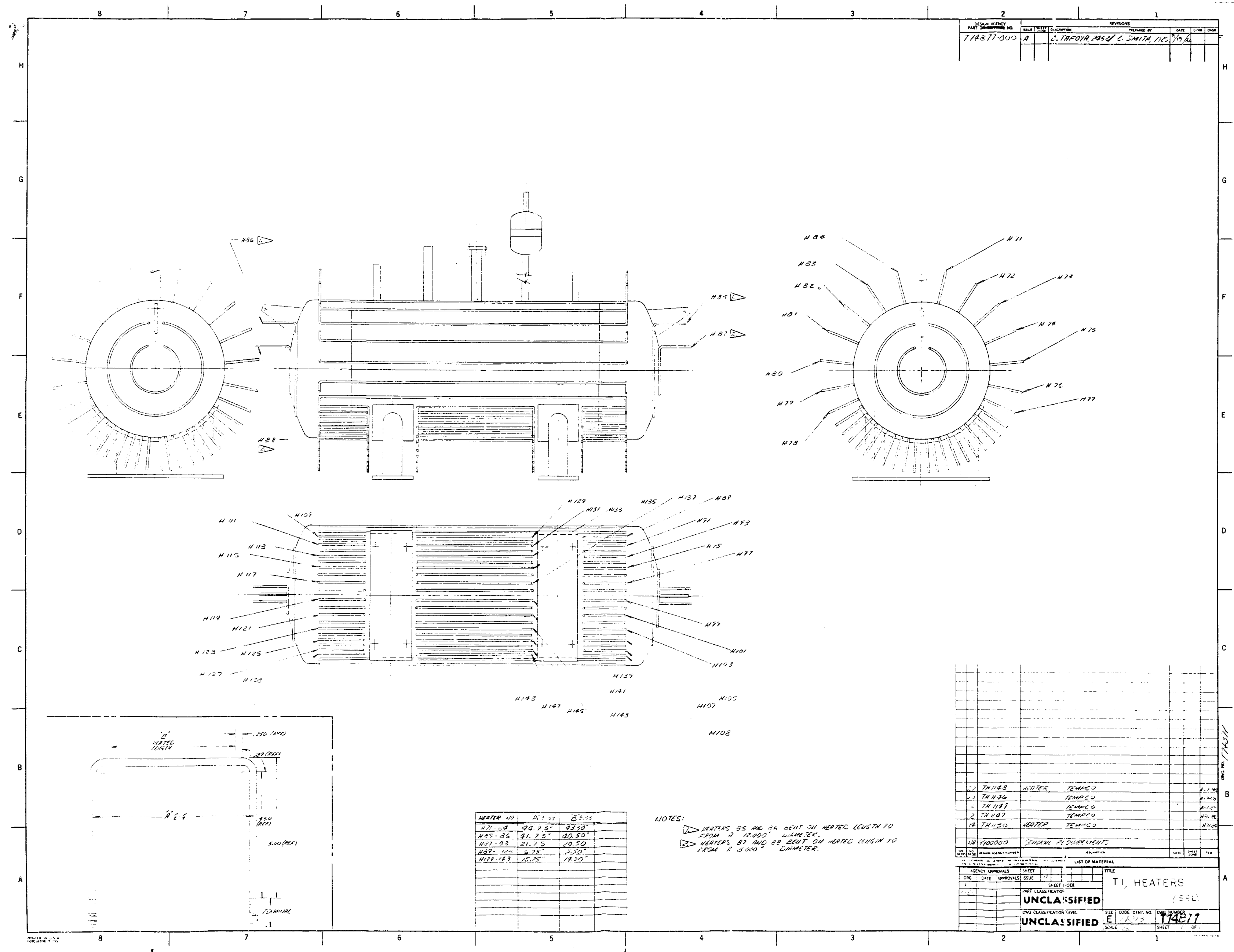




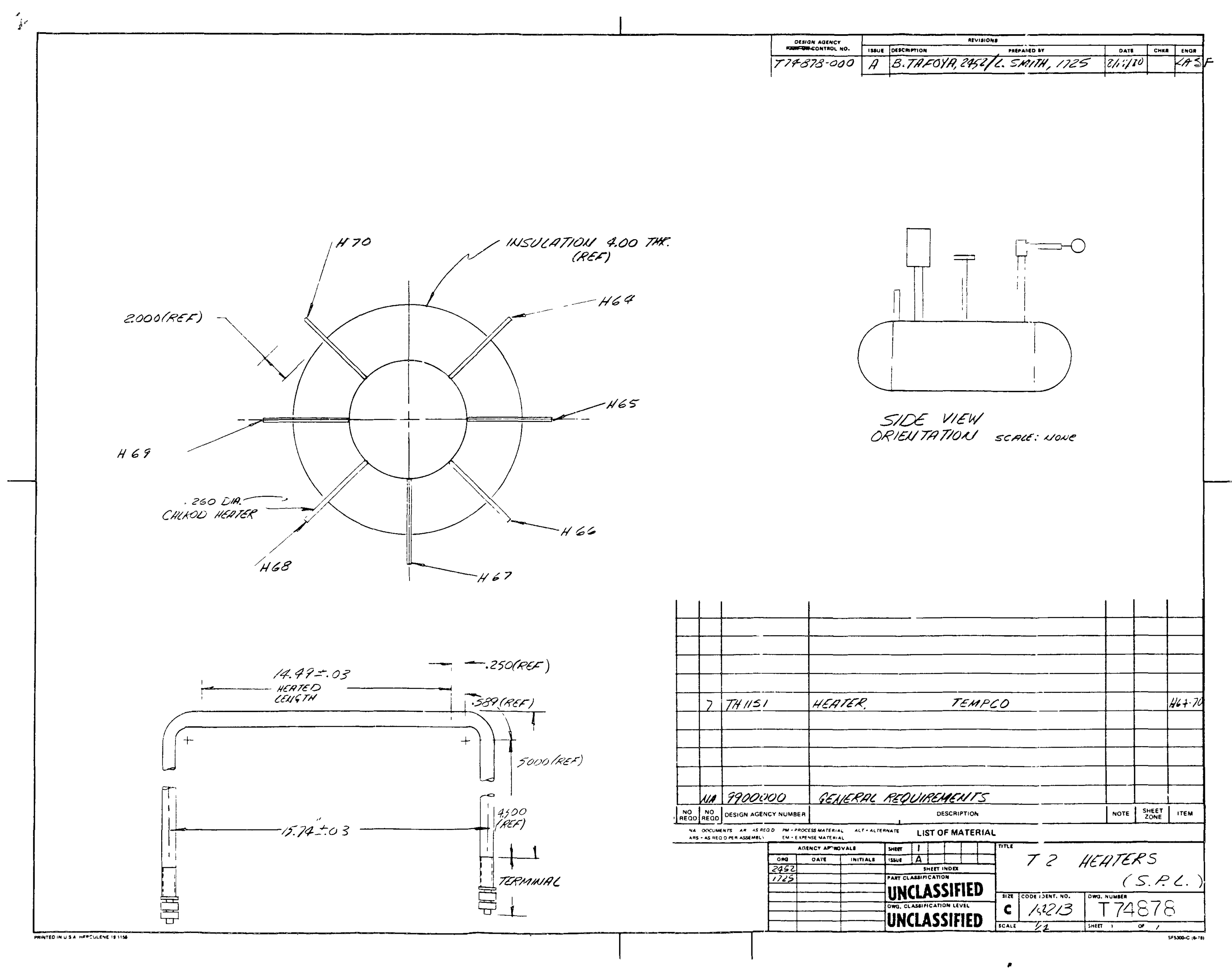




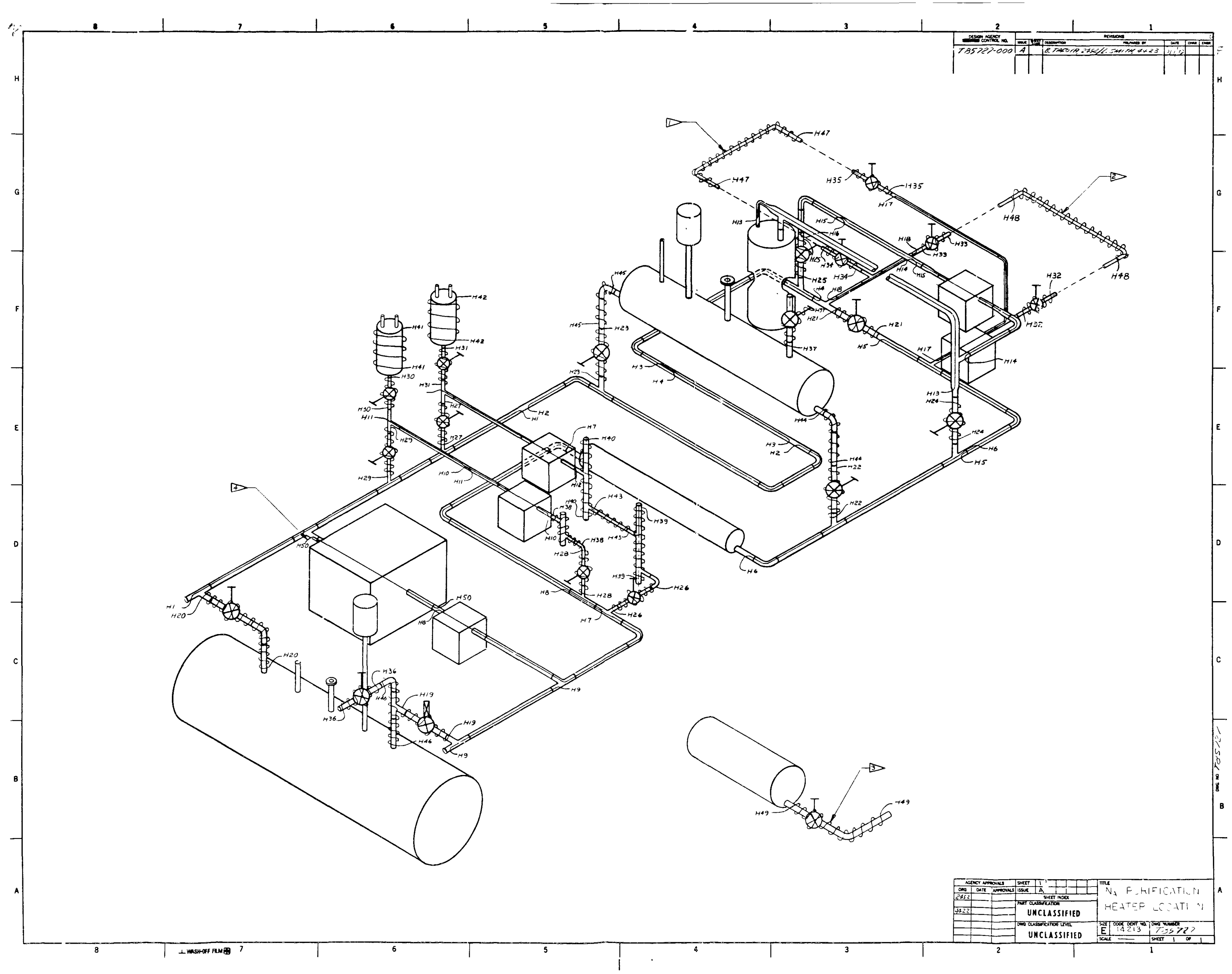





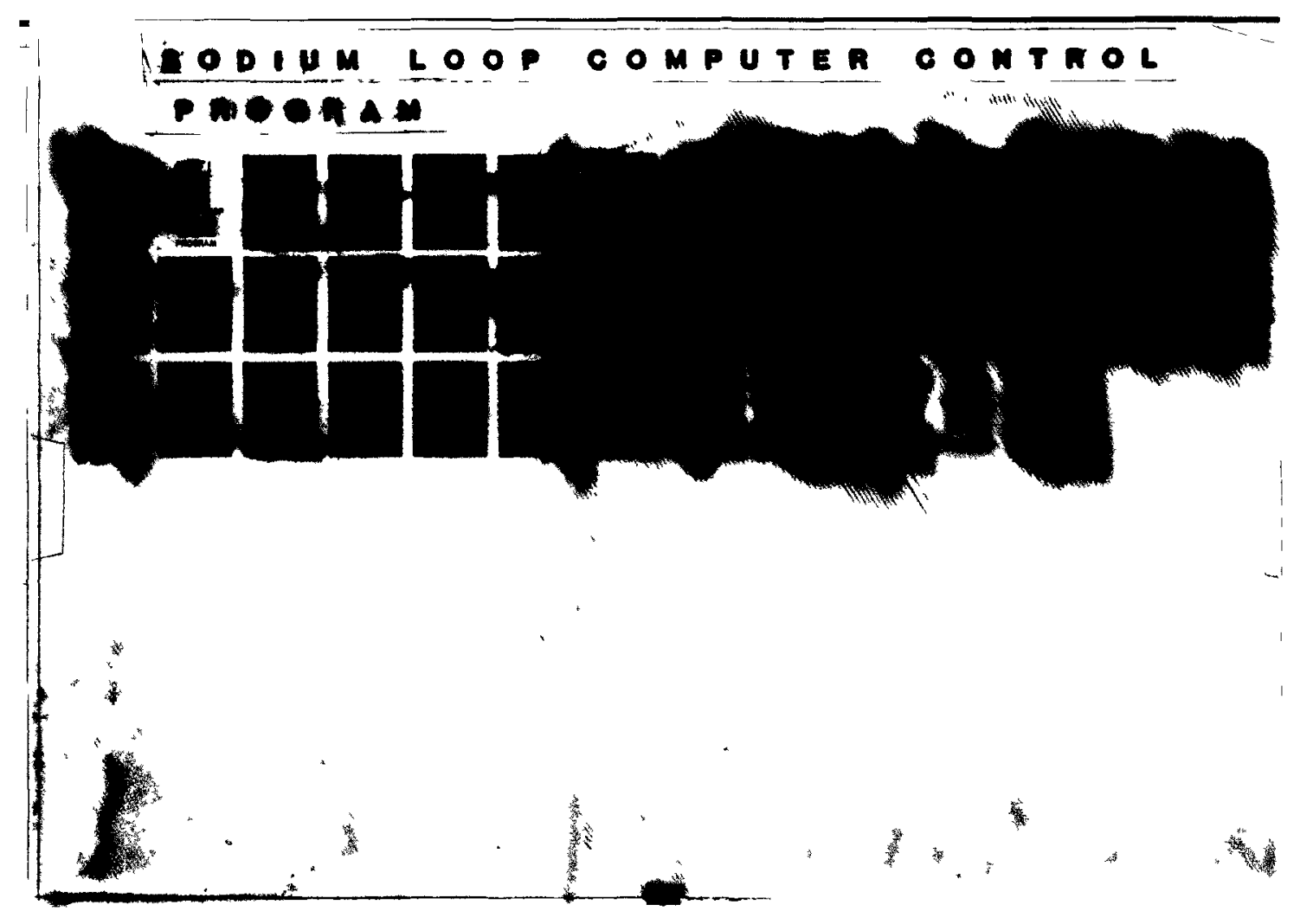

LOW ACID PAPER S/N 693452 


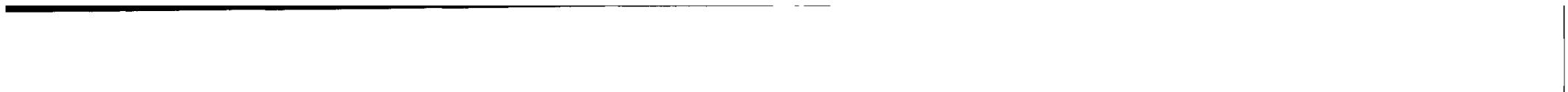

- 


\section{DISTRIBUTION :}

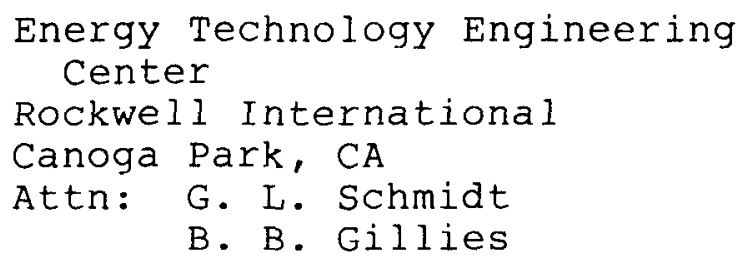


DISTRIBUTION (cont)

8310 R. W. Rohde

8450 J. B. Wright

8214 M. A. Pound

3141 L. J. Erickson (5)

3151 W. L. Garner (3)

For DOE/TIC (Unlimited Release)

DOE/TIC (25)

(C. H. Dalin, 3154-3) 